\title{
Analysis of Sn-Bi Solders: X-ray Micro Computed Tomography Imaging and Microstructure Characterization in Relation to Properties and Liquid Phase Healing Potential
}

\author{
Georg Siroky ${ }^{1, *} \mathbb{1}$, Elke Kraker ${ }^{1}$, Jördis Rosc ${ }^{1}$, Dietmar Kieslinger ${ }^{2}$, Roland Brunner ${ }^{1}$, \\ Sybrand van der Zwaag ${ }^{3}{ }^{\mathbb{D}}$, Ernst Kozeschnik ${ }^{4}{ }^{(\mathbb{D}}$ and Werner Ecker ${ }^{1}{ }^{\mathbb{D}}$ \\ 1 Materials Center Leoben Forschung GmbH (MCL), Roseggerstraße 12, 8700 Leoben, Austria; \\ elke.kraker@mcl.at (E.K.); joerdis.rosc@mcl.at (J.R.); roland.brunner@mcl.at (R.B.); werner.ecker@mcl.at (W.E.) \\ 2 ZKW Elektronik GmbH, Samuel Morse-Straße 18, 2700 Wiener Neustadt, Austria; \\ dietmar.kieslinger@zkw-electronic.at \\ 3 Faculty of Aerospace Engineering, TU Delft, Kluyverweg 1, 2629 Delft, The Netherlands; \\ s.vanderzwaag-1@tudelft.nl \\ 4 Institute of Materials Science and Technology, TU Wien, Getreidemarkt 9, 1060 Wien, Austria; \\ ernst.kozeschnik@tuwien.ac.at \\ * Correspondence: georg.siroky@mcl.at; Tel.: +43-3842-4592-2550
}

\section{check for}

updates

Citation: Siroky, G.; Kraker, E.; Rosc, J.; Kieslinger, D.; Brunner, R.; van der Zwaag, S.; Kozeschnik, E.; Ecker, W. Analysis of Sn-Bi Solders: X-ray Micro Computed Tomography Imaging and Microstructure Characterization in Relation to Properties and Liquid Phase Healing Potential. Materials 2021, 14, 153. https://doi.org/10.3390/ma14010153

Received: 27 November 2020 Accepted: 28 December 2020 Published: 31 December 2020

Publisher's Note: MDPI stays neutral with regard to jurisdictional clai$\mathrm{ms}$ in published maps and institutional affiliations.

Copyright: (C) 2020 by the authors. Licensee MDPI, Basel, Switzerland. This article is an open access article distributed under the terms and conditions of the Creative Commons Attribution (CC BY) license (https:// creativecommons.org/licenses/by/ $4.0 /)$.
Abstract: This work provides an analysis of X-ray micro computed tomography data of $\mathrm{Sn}-\mathrm{xBi}$ solders with $x=20,30,35,47,58 \mathrm{wt} . \% \mathrm{Bi}$. The eutectic thickness, fraction of eutectic and primary phase are analyzed. Furthermore, the 3D data is evaluated by means of morphology parameters, such as, shape complexity, flatness, elongation and mean intercept length tensor. The investigated alloys are categorized in three groups based on their morphology, which are described as "complex dominant", "complex- equiaxed" and "mixed". The mechanical behavior of Sn-Bi alloys in the semisolid configuration and the correlation with microstructural parameters are discussed. A varying degree of geometric anisotropy of the investigated alloys is found through the mean intercept length tensor. Representative volume element models for finite element simulations (RVE-FEM) are created from tomography data of each alloy to analyze a correlation of geometric and elastic anisotropy. The simulations reveal an elastic isotropic behavior due to the small difference of elastic constants of primary and eutectic phase. A discussion of properties in the semi-solid state and liquid phase healing is provided.

Keywords: solder; X-ray; computed tomography; morphology; anisotropy; FEM; healing; semi-solid; elastic; RVE

\section{Introduction}

Efforts to reduce the environmental impact of microelectronic products led to the development of lead-free solder alloys with varying content of $\mathrm{Ag}, \mathrm{Bi}, \mathrm{In}, \mathrm{Cu}, \mathrm{Ga}$ and $\mathrm{Zn}$ among other alloying elements [1-6]. The effort to reduce the environmental impact of $\mathrm{Pb}$ containing solders led to several alloys of varying $\mathrm{Sn}, \mathrm{Ag}$ and $\mathrm{Cu}$ content [7]. Recently, low melting point solders gained interest in the research community, where the Sn-Bi system is a promising candidate for soldering of temperature-sensitive components [2]. Studies investigated Sn-Bi alloys with respect to alloying elements [8-10], thermal parameters [11], magnetic stirring [12] and directional solidification [13,14]. The effect of In addition in Sn-Bi alloys on melting point and mechanical properties was shown by Wu et al. [8] and microstructural effects due to $\mathrm{Cu}$ and $\mathrm{Ag}$ additions were investigated by Silva et al. [9]. A strengthening effect of Ag addition to Sn-Bi alloys was reported by Ren et al. [10]. Elastic properties and their temperature-dependence were investigated by means of pulse echo overlap method [12], ultrasonic transmission $[15,16]$ and nano-indentation $[3,17]$. Despite 
the thorough mechanical characterization, a 3D microstructural analysis of $\mathrm{Sn}-\mathrm{Bi}$ alloys based on tomographic data is missing in literature.

Micro X-ray computed tomography $(\mu-X C T)$ imaging offers a non-destructive spatial analysis of materials and parts [18]. It was applied on solder materials to investigate several microstructural features such reflow porosities [19-21] or phase morphology [22-26]. The size distribution of spherical reflow porosities in solder joints was reported by Jiang et al. [19] and Rauer et al. [20]. Shi et al. [21] investigated the deformation of reflow porosities in fatigue experiments with $\mu$-XCT imaging and finite element simulations. A combined approach of $\mu$-XCT imaging and focused ion beam (FIB) tomography was reported by Yazzie et al. [22] and highlighted the local microstructure and morphology of Sn-rich solders. The size distribution and morphology of intermetallic phases in Snrich solders was reported by Kaira et al. [24] and the primary phase dendrites in $\mathrm{Sn}-\mathrm{Pb}$ solder were assessed with $\mu$-XCT imaging by Mertens et al. [25]. A three-dimensional morphometric characterization of $\mathrm{Sn}-\mathrm{Ag}$-Cu solder microstructures was reported by Maleki at al. [26]. The microstructural evolution of flip-chip solder joints under electromigration were investigated by [27] using in-situ 3D laminography and finite element simulations. X-ray tomography data of solders was used for numerical modelling of thermal and mechanical properties, where Michael et al. [28] used tomography data to numerically investigate the thermal resistance of solder joints with respect to reflow porosities. The elasto-plastic response of Sn-Ag-Cu solders after aging was studied by Maleki et al. [26,29] and highlighted the possibility to compute the stress-strain response from tomography data. Besides these reported studies on thermal and mechanical behavior, other properties also depend on the microstructural morphology, such as semi-solid deformation [30-32], hot tearing $[33,34]$ or liquid phase healing $[35,36]$. These properties have not been reported in literature for $\mathrm{Sn}$-Bi alloys and it is the aim of the present work to provide the essential parameters to enable such studies.

The volumetric phase fraction and local grain or phase thickness are commonly evaluated parameters and can be determined from 2D- [37] and 3D measurements [25]. In addition, the mean intercept length (MIL) parameter is used to describe the geometric anisotropy [38]. It quantifies the number of phase boundaries along randomly oriented trajectories through the volume of interest (VOI). The degree of anisotropy $(D A)$ can be derived from the eigenvalues of the MIL tensor and provides a scalar measure with $D A=0$ representing an isotropic and $D A=1 \mathrm{a}$ perfectly aligned anisotropic microstructure [38]. A new morphology categorization was reported by Fang et al. [39], which is based on the shape complexity parameter $[40,41]$, elongation and flatness $[42,43]$. They determined shape classes based on these three morphology parameters and distinguished among spherical, equiaxed, rod, sheet and complex shaped domains [39]. This enables the quantification of morphologic similarities among alloys and provides the basis for generic microstructure creation.

This study provides an analysis of several microstructural descriptors from $\mu$-XCT images. Five samples of varying Bi content $(20 \mathrm{wt} . \%, 30 \mathrm{wt} . \%, 35 \mathrm{wt} . \%, 47 \mathrm{wt} . \%$ and $58 \mathrm{wt} . \% \mathrm{Bi}$ ) and a microstructure representative of that obtained during industrial reflow processing are prepared. The reconstructed tomography data is segmented into Sn-rich primary- and Bi-rich eutectic phase and microstructural parameters are evaluated from the segmented tomography data, such as, eutectic phase fractions, mean intercept length of phase boundaries, volume to surface ratio, complexity parameter, flatness and elongation. The mechanical behavior of Sn-Bi alloys in the semi-solid state is discussed using the extracted morphology parameters and literature data. Representative volume element models for finite element simulations (RVE-FE) are derived from the $\mu$-XCT data for finite element simulations and the correlation between geometric and elastic anisotropy is investigated. The work ends with a morphology-based prediction of which alloy composition is most likely to yield the best liquid phase-assisted self-healing behavior. 


\section{Materials and Methods}

\subsection{Sample Preparation}

Alloys of composition Sn- 20, 30, 35, 47 and $58 \mathrm{wt} . \%$ Bi were prepared on an induction heat plate and held at $250{ }^{\circ} \mathrm{C}$ for $60 \mathrm{~min}$ for homogenization. Cylindrical samples of dimension $\varnothing 3 \mathrm{~mm} \times 10 \mathrm{~mm}$ were cast in a silicon mold and solidified under air cooling. The temperature in the silicon mold was measured using a contact thermometer. The temperature and cooling rates in the mold are illustrated in Figure 1. The average cooling rate in the initial phase of solidification was $1.5 \mathrm{~K} / \mathrm{s}$. The solidus temperature of $T_{\mathrm{s}}=138^{\circ} \mathrm{C}$ was reached after $55 \mathrm{~s}$. Cylindrical pins of $\varnothing 0.5 \mathrm{~mm} \times 1 \mathrm{~mm}$ were machined from the as-cast samples on a lathe under oil cooling. The pins were glued to cylindrical glass rods for positioning in the $\mu$-XCT setup. Samples were prepared for SEM (scanning electron microscopy) imaging by mechanical grinding and polishing for comparison with measurements from $\mu$-XCT data. The homogeneity of the sample microstructure was assessed by measuring the eutectic phase fraction from SEM cross-sections, where sample dependencies were insignificant.

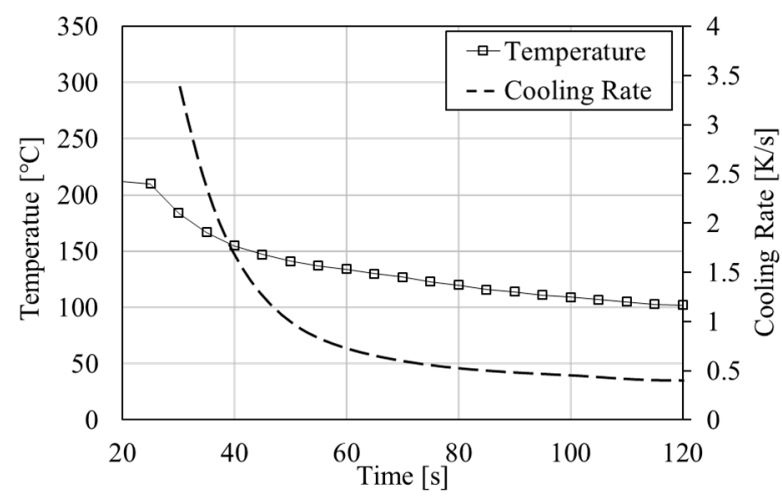

Figure 1. Temperature (solid squares) and cooling rate (dashed) during sample casting Sn-20 wt.\% Bi sample.

Images of sample cross-sections were obtained on a SEM (FEI Philips XL30, Philips, Amsterdam, The Netherlands) in electron back scatter mode (BSE) and with 20kV acceleration voltage.

\subsection{Imaging and Segmentation}

The samples were scanned on a lab-scale $\mu$-XCT device (GE nanotom $\mathrm{m}$, General Electric, Boston, MA, USA) with an isotropic voxel size of about $1.8 \mu \mathrm{m}$. The acceleration voltage was set to $116 \mathrm{kV}$ and the $\mathrm{X}$-ray tube current was $100 \mu \mathrm{A}$. These settings were chosen to allow transmission in the samples and to minimize image artefacts. No pre-filters were applied on the X-ray tube and the VOI of scanned samples had the dimensions of approximately $400 \times 400 \times 1050 \mu^{3}$.

The Sn-rich primary phase and Bi-rich eutectic phase were segmented with the commercial image analysis software Avizo 2019.1 (www.thermofischer.com). Prior to segmentation, the signal-to-noise ratio was enhanced by applying a median filter with a kernel of $3 \times 3 \times 3$ voxels, which improves the detectability of phase boundaries. The segmentation of dendrites was achieved using the top-hat transform algorithm. This includes two steps, first, a closing operation on the grey value image and second, the selection of a threshold value to detect the dark primary phase regions in the data. This approach reduces noise, improves the detectability of structures on the length scale of several voxels and reduces non-uniformities caused by beam-hardening artefacts.

The segmentation delivered a binary data set which consists of the primary phase and the surrounding eutectic phase. A representative grey value image after image acquisition and the segmented primary phase are illustrated in Figure $2 a, b$, respectively. The comparison of grey value and segmented image in Figure $2 \mathrm{a}, \mathrm{b}$ shows that morphological 
features, such as, dendrites or phase boundaries are well represented. The segmented data is compared with scanning electron microscopy (SEM) images to verify the eutectic thickness. Furthermore, phase fractions from $\mu$-XCT measurements are compared with CALPHAD (Calculations of Phase Diagrams) calculations using the software package MatCalc 6.03 (http:/ / matcalc.at) with the thermodynamic database COST 531 [44], to quantify the agreement of theoretical and measured phase fractions. A phase diagram of the binary Sn-Bi system is provided in Figure A1 (Appendix A).

(a)

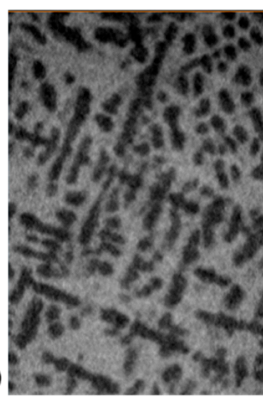

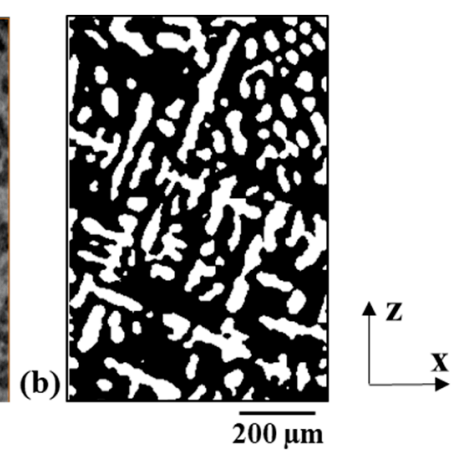

Figure 2. Representative image obtained in the $x-z$ plane from the $3 \mathrm{D}$ data for the $\mathrm{Sn} 58 \mathrm{wt} . \% \mathrm{Bi}$ alloy. (a) Grey value image displays the primary phase (dark grey) and eutectic phase (light grey). (b) Corresponding segmented primary phase (white).

\subsection{Microstructural Parameter}

The segmented images were analyzed using the open-source package ImageJ 1.53c [45-47]. Connected domains were analyzed and labelled with a random color lookup table for rendering. Several microstructural quantities are extracted from the segmented 3D data, such as, eutectic volume fraction, eutectic surface fraction, eutectic thickness, MIL tensor, degree of anisotropy $(D A)$, volume of eutectic $\left(V_{\mathrm{e}}\right)$, total VOI volume $\left(V_{\text {total }}\right)$ and surface area of eutectic $\left(A_{\mathrm{e}}\right)$. The eutectic volume fraction, $\phi_{\mathrm{e}}$, is calculated with

$$
\phi_{\mathrm{e}}=\frac{V_{\mathrm{e}}}{V_{\text {total }}}
$$

and compared with CALPHAD calculations. The eutectic surface fraction, $\psi_{\mathrm{e}}$, is obtained through

$$
\psi_{\mathrm{e}}=\frac{A_{\mathrm{e}}}{V_{\text {total }}}
$$

The eutectic thickness, $t_{\mathrm{e}}$, is defined according to Hildebrand and Rüegsegger [47] as the largest diameter of a sphere completely inside the eutectic phase, which is written as

$$
t_{\mathrm{e}}\left(x_{\mathrm{e}}\right)=2 \cdot \max \left(\left\{r \mid x_{\mathrm{e}} \in \operatorname{sph}(x, r) \subseteq \Omega, x \in \Omega\right\}\right)
$$

where $\Omega \subset R^{3}$ is the set of all points within the eutectic structure and $x_{\mathrm{e}} \in \Omega$ is an arbitrary point in the eutectic structure. The expression $\operatorname{sph}(x, r)$ define the points inside a sphere with center $x$ and radius $r$. A possible VOI size-dependence of several extracted parameters, such as, $\phi_{\mathrm{e}}, A_{\mathrm{e}}, t_{\mathrm{e}}$ or $\mathrm{DA}$ is provided in the Appendix $\mathrm{B}$ in Figures A3-A6 respectively. A morphology analysis based on the shape complexity, elongation and flatness was performed following the classifications found to be useful in describing the healing of damage during creep loading of steels [39]. The shape complexity parameter, $\Omega_{3}$, is calculated as

$$
\Omega_{3}=\frac{A}{\pi^{\frac{1}{3}}(6 V)^{\frac{2}{3}}}
$$

with $A$ and $V$ being the surface area and volume of the segmented domain, respectively. Furthermore, the elongation and flatness are evaluated based on the moment of inertia, 
$I_{j}$, of an equivalent ellipsoid. The semi-axes of the ellipsoid, $a_{j}$, are calculated from the eigenvalues of the inertia tensor, $I$, as

$$
a_{j}=\sqrt{\frac{5\left(\operatorname{tr}(I)-2 I_{j}\right)}{2 V}}
$$

The elongation is calculated accordingly with

$$
E=\frac{2 a_{1}}{a_{2}+a_{3}}
$$

and the flatness with

$$
F=\frac{a_{2}}{a_{3}}
$$

Five shape categories are defined according to their combination of $\Omega_{3}, E$ and $F$, which is summarized in Table 1. A discussion on the correlation of shape and morphology parameters is given in [39].

Table 1. Values for shape categorization based on complexity parameter $\Omega_{3}$, elongation $E$ and flatness F [39].

\begin{tabular}{cccc}
\hline & $\boldsymbol{E}$ & $\boldsymbol{F}$ & $\Omega_{3}$ \\
\hline Sphere & - & - & $\Omega_{3} \leq 1.15$ \\
\hline Equiaxed & $<5$ & $<5$ & $1.15<\Omega_{3} \leq 2.5$ \\
\hline Rod & $\geq 5$ & $<5$ & $1.15<\Omega_{3} \leq 2.5$ \\
\hline Sheet & - & $\geq 5$ & $1.15<\Omega_{3} \leq 2.5$ \\
\hline Complex & - & - & $\Omega_{3} \geq 2.5$ \\
\hline
\end{tabular}

An ellipsoid fit of the MIL tensor is computed [46] and the DA is calculated from the associated eigenvalues, $\lambda_{i}$, with

$$
D A=1-\frac{\min \left(\lambda_{i}\right)}{\max \left(\lambda_{i}\right)}
$$

\subsection{RVE-FEM Model}

Voxel-based RVE-FE models were created from $\mu$-XCT data to investigate the agreement with elastic mixing rules and a possible elastic anisotropy. The segmented binary images were converted into the mhd format and a voxel mesh was generated using the software package medtool 4.4 (www.dr-pahr.at/medtool). A coarsening factor of 3 was applied on the 3D data, leading to an average voxel size of $6 \mu \mathrm{m}$, where a convergence analysis with a coarsening factor ranging from 3 to 5 was performed. Cuboid models with $x, y$ and $z$ dimensions of $356 \mu \mathrm{m} \times 356 \mu \mathrm{m} \times 1029 \mu \mathrm{m}$ and kinematic periodic boundary conditions (PBC) were created in the commercial software package ABAQUS 6.19 (www.3ds.com). The microstructure was approximated with 596,991 elements of type C3D8. Material parameters for elastic properties of primary and eutectic phase were taken from literature [17] and values are provided in Table 2. The Young's moduli of microstructures with 20, 30, 47 and $58 \mathrm{wt} . \%$ Bi were evaluated numerically under uniaxial deformation in $\mathrm{x}-, \mathrm{y}$ - and $\mathrm{z}$ direction. For comparison with the $D A$ parameter, the elastic anisotropy is evaluated from simulations as

$$
D A_{\mathrm{el}}=1-\frac{\min \left(E_{i}\right)}{\max \left(E_{i}\right)}
$$

with $\min \left(E_{i}\right)$ and $\max \left(E_{i}\right)$ representing the minimal and maximal Young's modulus, respectively. 
Table 2. Elastic material parameters of RVE-FE model [17].

\begin{tabular}{cc}
\hline Property & Value [Unit] \\
\hline Young's modulus primary phase & $50.0[\mathrm{GPa}]$ \\
\hline Poisson number primary phase & $0.33[-]$ \\
\hline Young's modulus eutectic phase & $40.0[\mathrm{GPa}]$ \\
\hline Poisson number eutectic phase & $0.33[-]$ \\
\hline
\end{tabular}

The linear and inverse rules of mixture were evaluated according to [48] for comparison with RVE-FE results.

\section{Results}

\subsection{Tomographic Rendering}

Figure 3 shows a rendering of the segmented eutectic phase from $\mu$-XCT data of five alloy compositions, where the color indicates connected domains. The Sn-20 wt.\% Bi sample in Figure 3 a reveals the highest fragmentation with isolated islands of eutectic phase. The Sn-30 wt.\% Bi sample in Figure 3b exhibits fewer disconnected regions, where a large connected eutectic domain is indicated in blue. The samples with 35,47 and 58 wt.\% Bi are illustrated in Figure $3 c, d, f$, respectively. These latter compositions show a connected network of eutectic phase across the entire VOI.

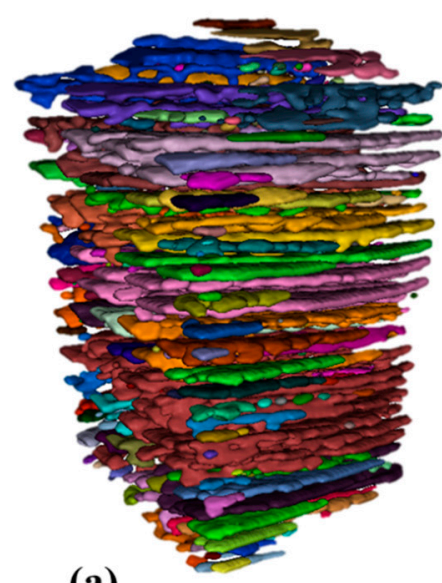

(a)

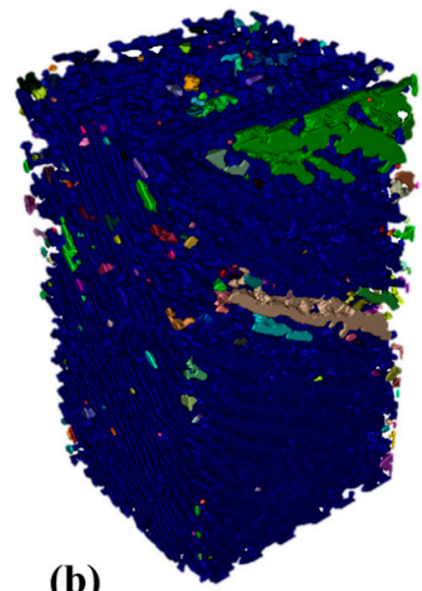

(b)
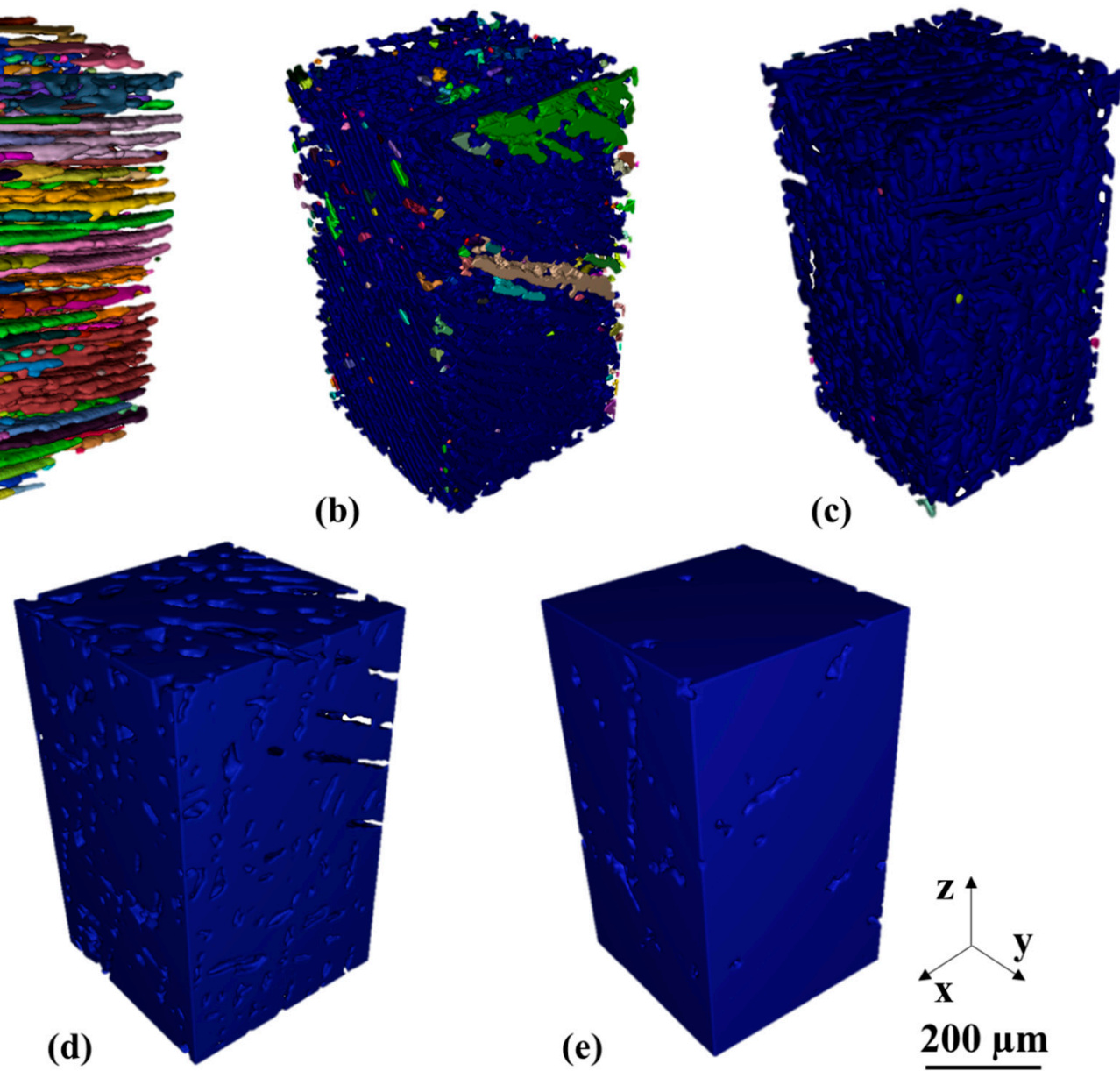

Figure 3. Segmented eutectic phase obtained from $\mu$-XCT. Color code: Each color represents a single connected phase. (a) Sn-20 wt.\% Bi (b) Sn-30 wt.\% Bi (c) Sn-35 wt.\% Bi (d) Sn-47 wt.\% Bi (e) Sn-58 wt.\% Bi. 
Complementary images of the primary phase are shown in Figure 4. A network is indicated by red colored domains in Figure $4 a-c$. A comparison among Figures $3 c$ and $4 \mathrm{c}$ of the Sn-35 wt.\% Bi alloy shows an interpenetrating network of the primary and eutectic phases with a low fragmentation of domains. The Sn- $47 \mathrm{wt} . \%$ Bi and Sn- $58 \mathrm{wt} . \% \mathrm{Bi}$ reveal separated dendritic structures of primary phase in Figure $4 c, d$, respectively. Despite the lower primary phase fraction in the Sn- $58 \mathrm{wt} . \%$ Bi alloy, a connectivity of dendritic structures is visible. Furthermore, the primary and secondary dendrites are captured in Figure 4e.
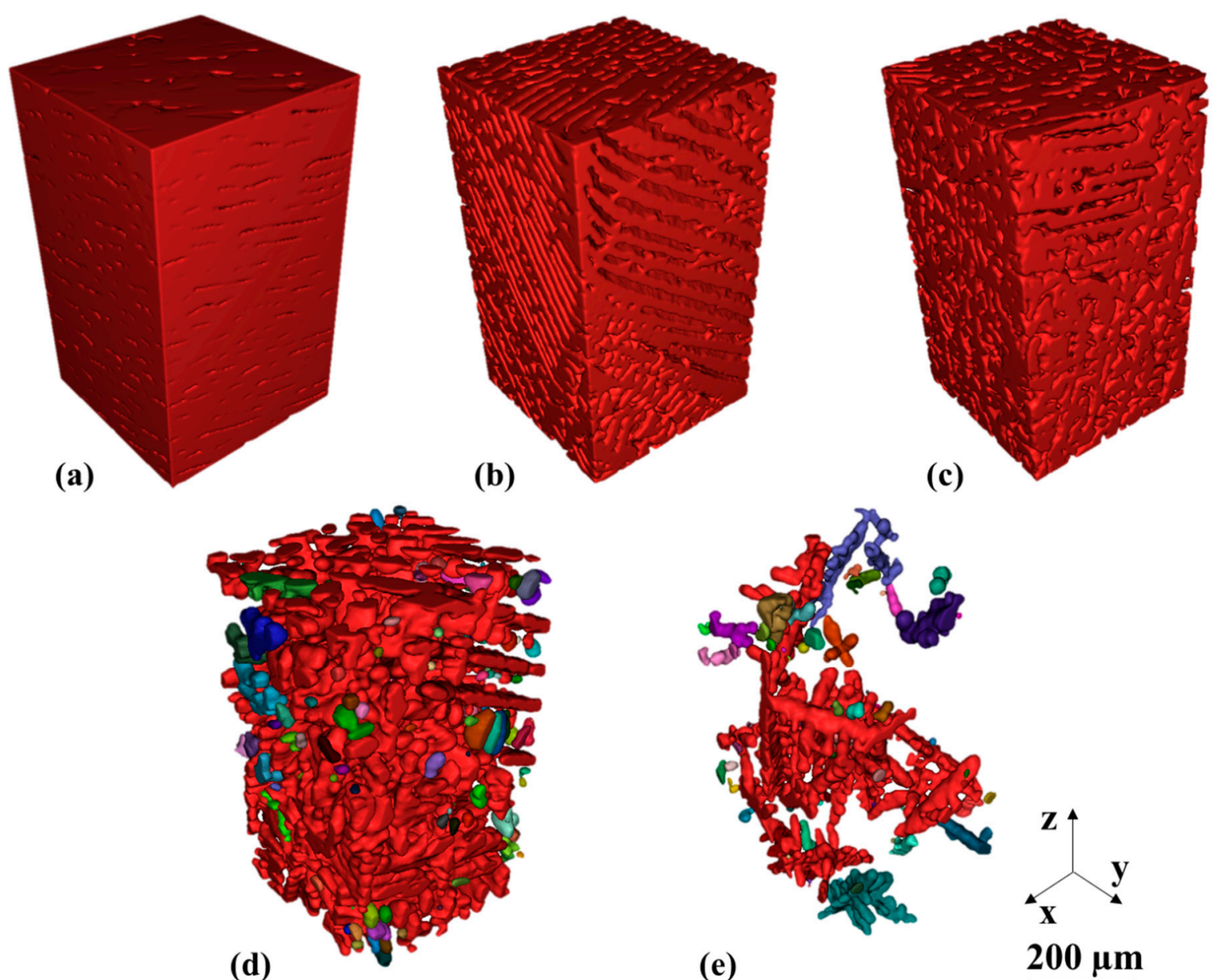

(e)

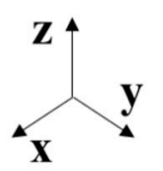

$200 \mu \mathrm{m}$

Figure 4. Segmented primary phase obtained from $\mu$-XCT. Color code: Each color represents a single connected phase. (a) Sn-20 wt.\% Bi (b) Sn-30 wt.\% Bi (c) Sn-35 wt.\% Bi (d) Sn-47 wt.\% Bi (e) Sn-58 wt.\% Bi.

\subsection{Volume Fractions}

The eutectic volume fraction is extracted from the $\mu$-XCT data and illustrated in Figure 5, where a comparison with CALPHAD calculations and the generated RVE-FE models is given. Figure 5 a shows a correlation between the equilibrium eutectic fraction (black solid) with $\mu$-XCT (green triangles) and RVE-FE (red squares) values. The $\mu$-XCT data captures the increasing eutectic fraction, with slight deviations from the predicted CALPHAD phase fractions (black solid line). The deviations seem random, with compositions 20, 30 and $47 \mathrm{wt} . \%$ Bi underestimating and 35 and $58 \mathrm{wt} . \%$ overestimating the theoretical eutectic fraction. Due to the image coarsening of the RVE-FE models, these trends are further amplified. Figure $5 b$ shows the error compared with CALPHAD calculations of $\mu$-XCT and RVE-FE data. The deviation of the $\mu$-XCT data remains below $10 \%$ for most alloys except the Sn- $47 \mathrm{wt} . \%$ Bi composition. The same holds for the RVE-FE data, whereas the $\mathrm{Sn}-35 \mathrm{wt} . \% \mathrm{Bi}$ alloy deviates considerable with $20 \%$. This originates from an 
unfavorable approximation due to the voxel-mesh. A refinement of the voxel-mesh would lead to a better representation of the eutectic fractions. However, a limit of about $5 \times 10^{6}$ elements prevents a further refinement and the Sn-35 wt.\% Bi alloy was omitted from simulations. A comparison with Scheil calculations showed similar results with deviations from the theoretical values of about $10 \%$. Results of the Scheil analysis are given in the Figure A2 and a variation of VOI and its effect on the volume fraction is given in Figure A3.
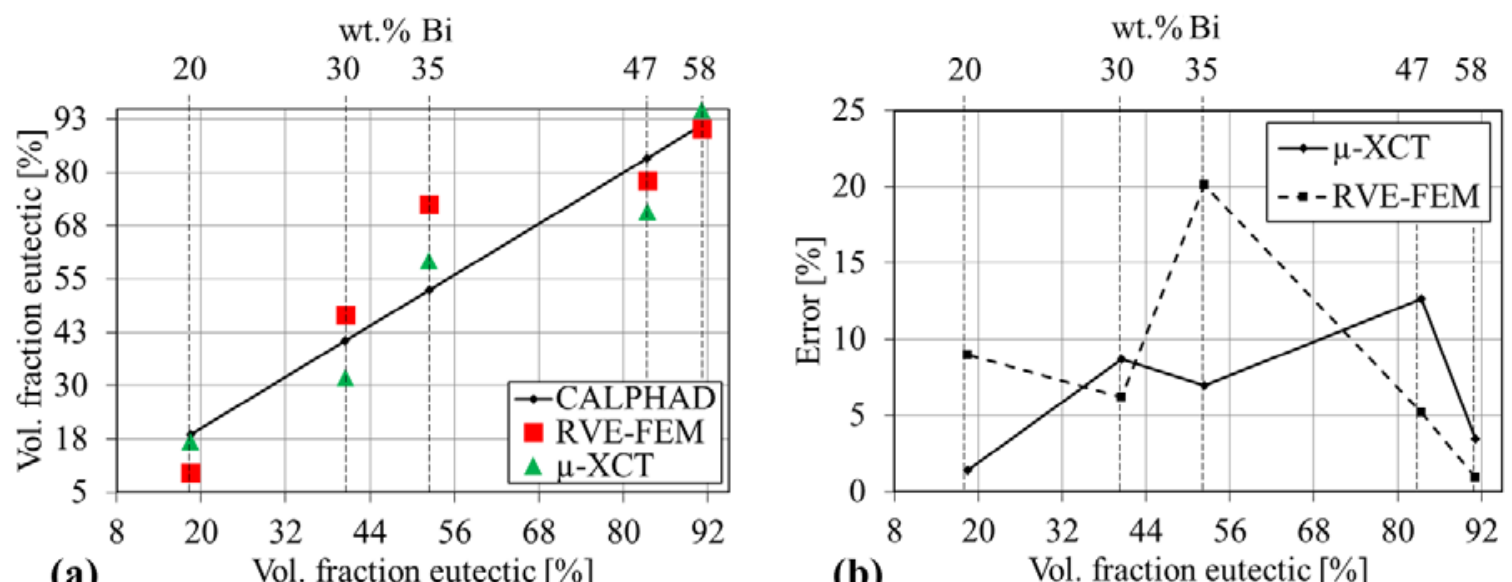

Figure 5. Eutectic volume fraction obtained from CALPHAD calculations, image analysis of $\mu$-XCT data and the RVEFE model. (a) eutectic volume fraction over composition (b) relative error of $\mu$-XCT data and RVE-FE model based on equilibrium CALPHAD calculations over composition.

\subsection{Eutectic Thickness}

The eutectic thickness determined from $\mu$-XCT data is shown in Figure 6. The eutectic thickness ranges from $3.6 \mu \mathrm{m}$ for the Sn-20 wt.\% Bi alloy to $73 \mu \mathrm{m}$ for the Sn-58 wt.\% Bi alloy. The data indicates a linearly increasing eutectic thickness among alloys with 20 , 30, 35 and 47 wt.\% Bi content. The Sn- 58 wt.\% Bi alloy shows the largest mean eutectic thickness and highest scatter of the measured values. Furthermore, a steep increase of mean eutectic thickness is observed from 47 to $58 \mathrm{wt} . \% \mathrm{Bi}$. The large scatter might arise from the dendritic microstructure and the large eutectic network observed in Figure 4e.

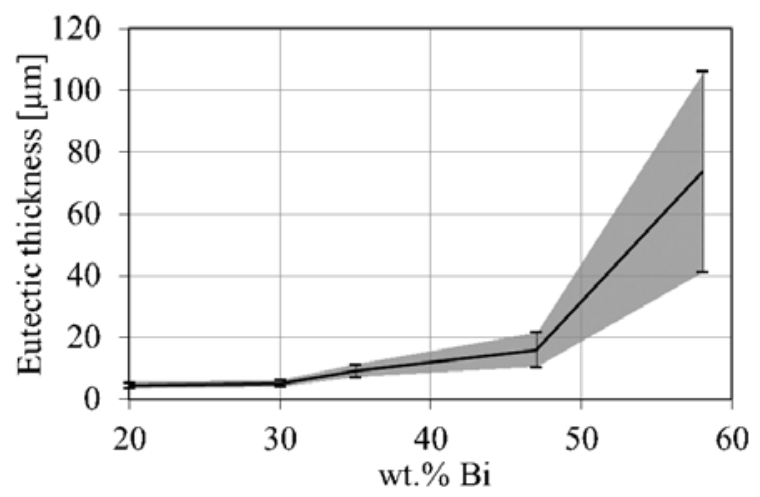

Figure 6. Eutectic phase thickness obtained from $\mu$-XCT measurements as a function of Bi content. Error bars indicate the standard deviation of eutectic thickness.

\subsection{Morgphology Parameters}

The morphology parameters $\Omega_{3}, E, F$ of each Sn-Bi alloy are given in Figures 7 and 8. The analysis shows that their microstructure is composed of equiaxed-, complex-, rod- and sheet-shaped domains. The shape complexity, $\Omega_{3}$, over volume is presented in Figure 7 . The illustrated data points represent each segmented sub-domain and its corresponding 
shape class. The Sn-20 wt.\% Bi alloy in Figure 7a is composed of equiaxed, complex, rod and sheet domains, where sheet and rod-like structures tend towards larger sub-volumes of $10^{3}-10^{6} \mu \mathrm{m}^{3}$. The equiaxed and complex-shaped domains are spread across the total volume range. The other alloys of 30, 35, 47 and $58 \mathrm{wt} . \%$ Bi in Figure $7 \mathrm{~b}-\mathrm{e}$, respectively, reveal similar complexity values. Each alloy contains a complex-shaped outlaying data point with a volume of around $10^{7} \mu \mathrm{m}^{3}$, which is the connected network of primary and eutectic phase. The majority of the data points is equiaxed-shaped with a volume of $10-10^{5} \mu \mathrm{m}^{3}$.
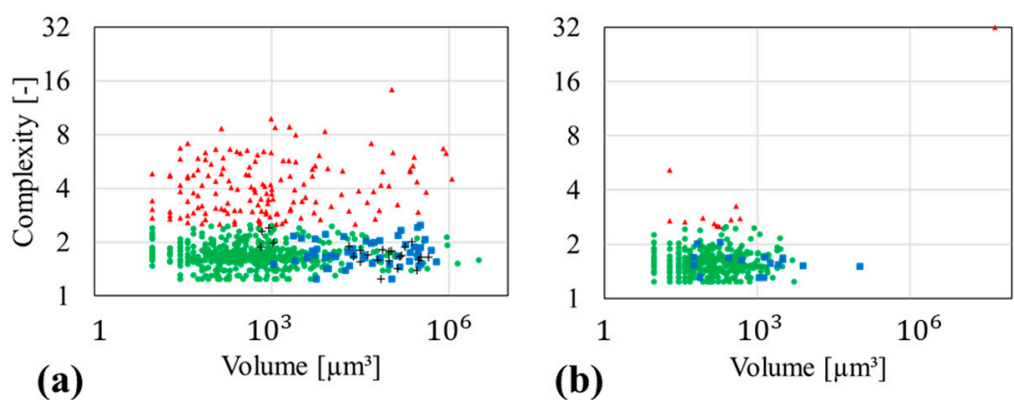

(b)
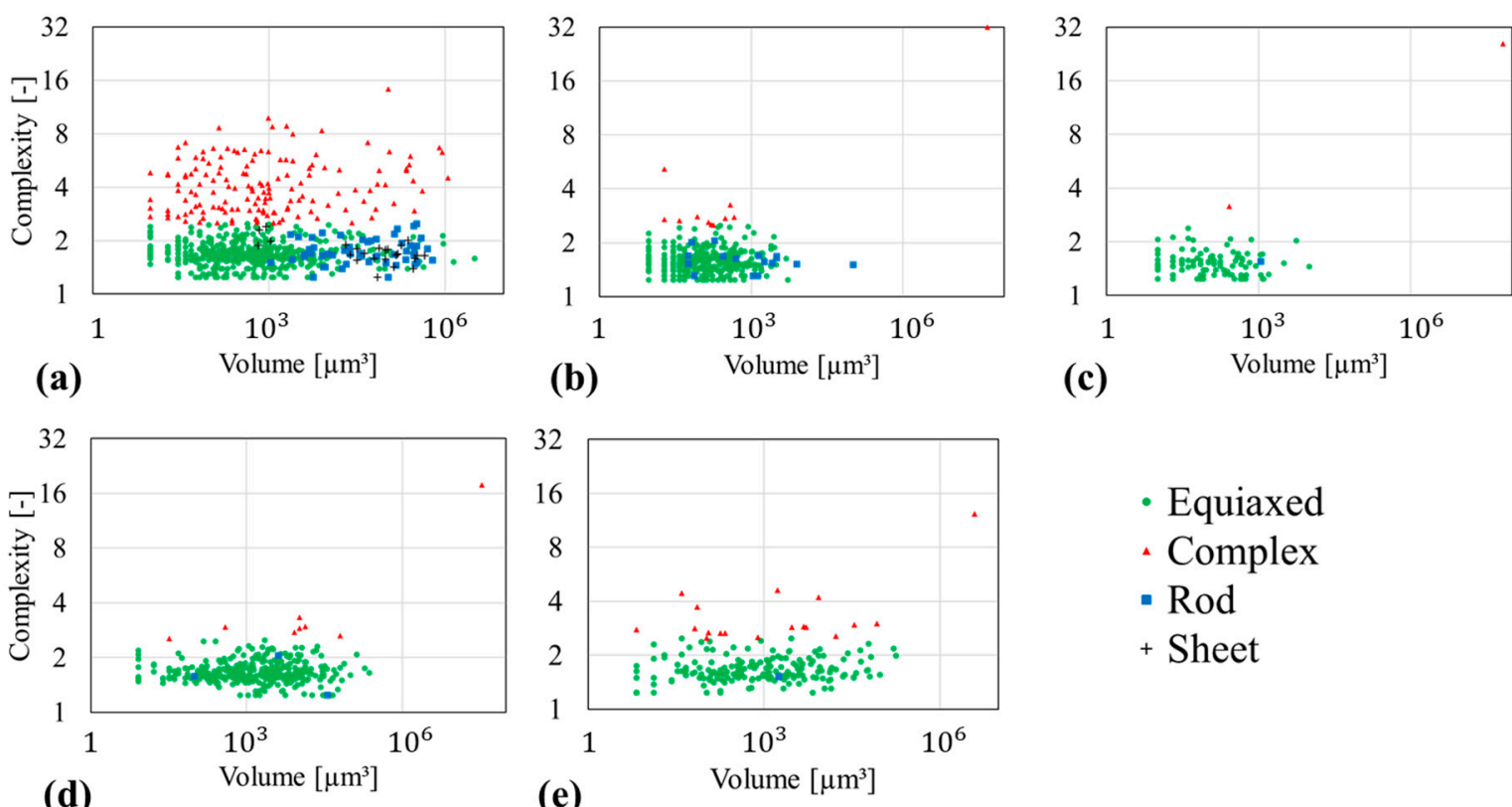

- Equiaxed

- Complex

- Rod

+ Sheet

Figure 7. Calculated complexity parameter based on the segmented $\mu$-XCT data as a function of the domain volume for Sn-Bi alloys. Morphology classes are equiaxed (green), complex (red), rod (blue), sheet (grey). (a) Sn-20 wt.\% Bi (b) Sn-30 wt.\% Bi (c) Sn-35 wt.\% Bi (d) Sn-47 wt.\% Bi (e) Sn-58 wt.\% Bi.

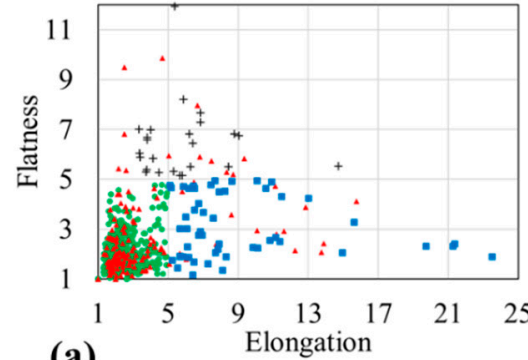

(a)

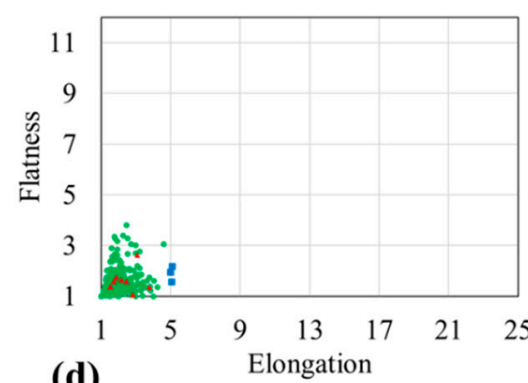

(d)

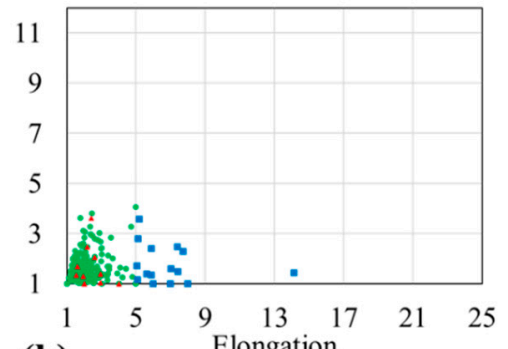

(b)

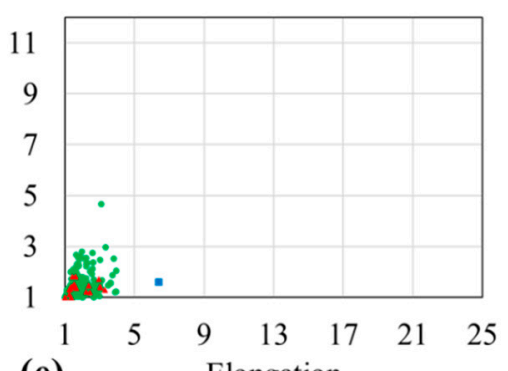

(e)

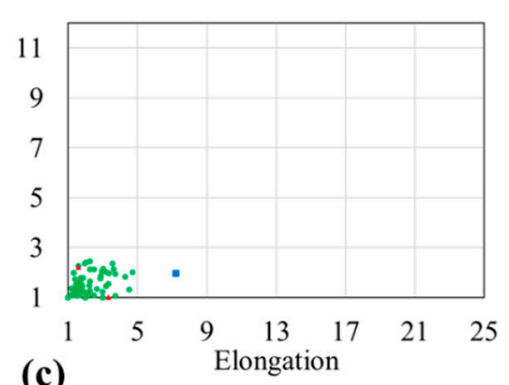

(c)

Figure 8. Flatness over elongation for Sn-Bi alloys based on the segmented $\mu$-XCT data. Morphology classes are equiaxed (green), complex (red), rod (blue), sheet (grey). (a) Sn-20 wt.\% Bi (b) Sn-30 wt.\% Bi (c) Sn-35 wt.\% Bi (d) Sn-47 wt.\% Bi (e) Sn-58 wt.\% Bi. 
Flatness over elongation in Figure 8 gives further morphological information on the microstructure. The Sn-20 wt.\% Bi alloy is illustrated in Figure 8a and shows the maximum range of elongation (1-25) and flatness (1-11) among the analyzed alloys. The rod-shaped structures have a maximum flatness $F$ of 5 and an elongation $E$ ranging from 5 to 25 . Most data points are equiaxed and complex-shaped, where low values of $E$ and $F$ indicate uniformly-shaped structures. The 30, 35, 47 and 58 wt.\% Bi alloys in Figure 8b-e reveal high similarity in the $E-F$ space, where, except for a few rod-shaped structures, most domains are equiaxed- and complex-shaped. Furthermore, the Sn-35 wt.\% Bi alloy in Figure 8c reveals the most isotropic geometry with $E_{\max }=3$ and $F_{\max }=7.2$ among the analyzed compositions. A large spread in $E-F$ space is associated with a strong geometric orientation. Low and similar values among $E$ and $F$ characterize isotropic microstructures.

\subsection{Geometric Anisotropy}

The geometric orientation is analyzed using the MIL tensor and $D A$ parameter, where $D A=0$ is spatial isotropy and $D A=1$ fully anisotropic [46]. Eigenvalues and eigenvectors of the ellipsoid on the MIL tensor are given in Appendix C in Table A1 and the respective ellipsoids are provided in Appendix $C$ in Figure A7. Figure 9 shows the $D A$ over composition, where the $\mathrm{Sn}-20 \mathrm{wt} . \% \mathrm{Bi}$ alloy reveals the highest degree of anisotropy. This is in agreement with the wide span of $E$ and $F$ in Figure 8 a, which indicated a flat and elongated microstructure. Furthermore, the Sn- 35 wt. \% Bi gives the lowest value of $D A=0.058$, which is reflected by a low spread of $E$ and $F$ values in Figure 8c. A VOI size variation with respect to $D A$ is given in Figure $\mathrm{A} 6$ and showed an insignificant variation with respect to VOI dimensions.

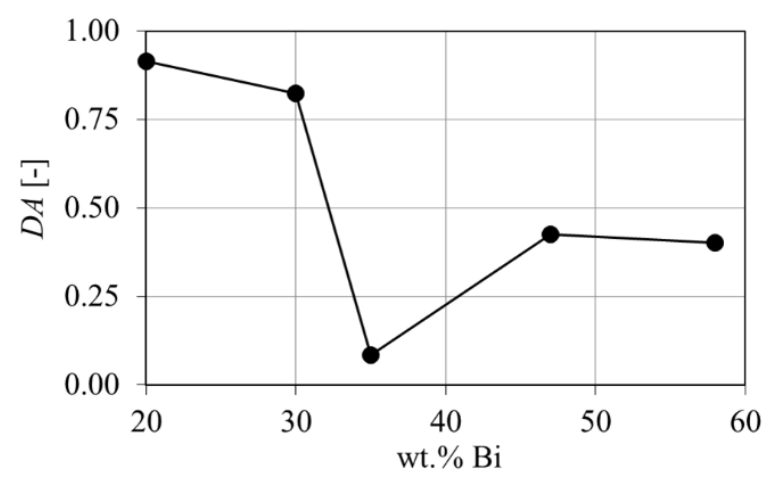

Figure 9. Calculated degree of anisotropy from $\mu$-XCT measurements over composition of Sn-Bi alloys.

\subsection{Computed Elastic Response}

In Figure 10, the Young's moduli calculated through RVE-FE models are shown (green, solid-dot). The analytical linear and inverse mixing rules were evaluated (dashed) for comparison, where graphs of linear and inverse mixing rule appear congruent due to the low difference in Young's moduli of primary and eutectic phase. Furthermore, values for Young's moduli reported in literature are shown as a benchmark for computed results. The RVE-FE model shows good agreement with results from the analytical mixing rules. The RVE-FE calculations in Figure 10 are also in good agreement with Young's moduli reported by Lu et al. [17] through nano-indentation and values by El-Daly [12] through pulsed echo overlap (PEO). Values of Wu et al. [8], Mokhtari et al. [49] and Lai et al. [50] show considerable deviation from the RVE-FE values arising from the specific measurement methods used, where tensile tests in particular underestimate the elastic properties. 


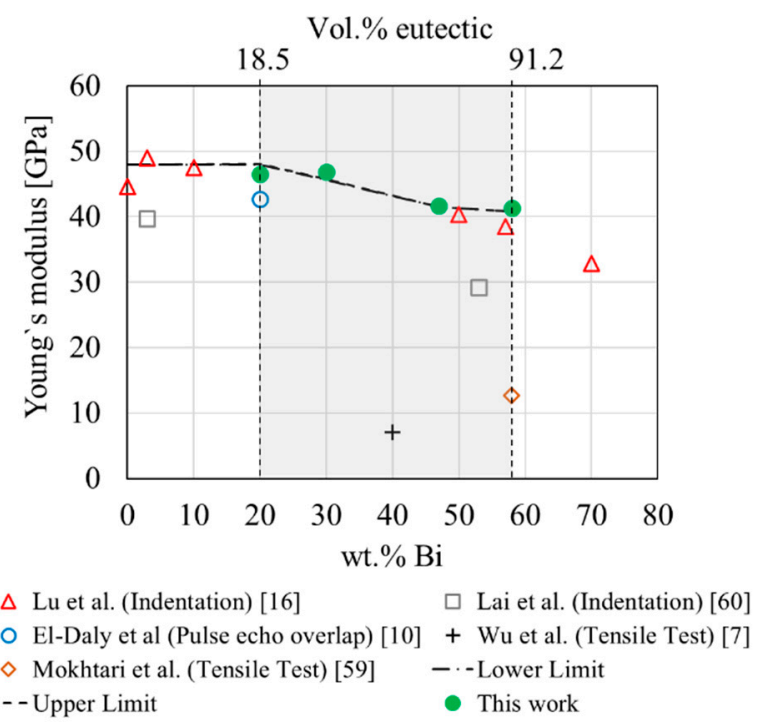

Figure 10. RVE-FE results, linear/inverse mixing rule and literature values of Young's modulus.

\section{Discussion}

\subsection{Eutectic Surface Fraction}

The eutectic surface fraction according to Equation (2) for the $\mu$-XCT data and RVE-FE models is given in Figure 11. The $\mu$-XCT data shows a maximum surface fraction for the Sn-35 wt.\% Bi alloy, which corresponds to the interpenetrating network of eutectic- and primary phase observed in Figures 3 and 4. Furthermore, it reveals that Sn-Bi alloys with around $50 \%$ eutectic phase fraction create the maximum number of phase boundaries. The RVE-FE model in Figure 11 properly reflects the tomography data. Yet, the surface fraction in the RVE-FE model is underestimated on average by roughly $50 \%$, which arises from the voxel approximation. Therefore, the model in its presented form has limitations with respect to properties that require a quantitative representation of phase boundaries. Nevertheless, the general trend is fulfilled for alloys with 20,30, 47 and $58 \mathrm{wt} . \% \mathrm{Bi}$. The phase boundary surface area with respect to VOI size is given in Figure A4.

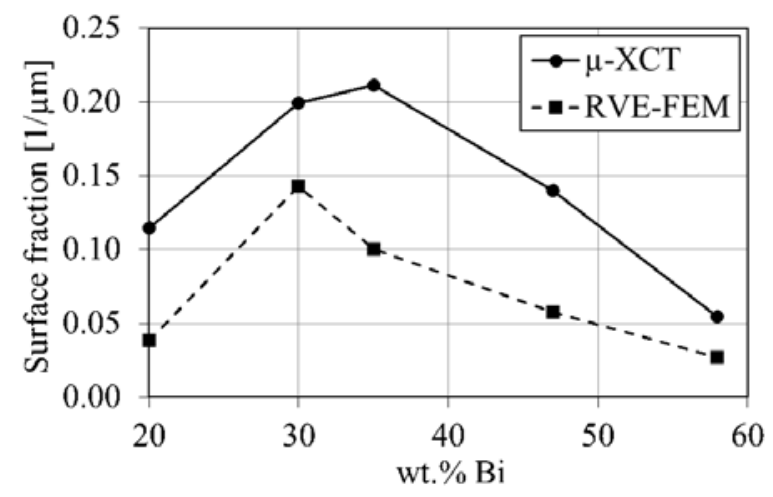

Figure 11. Eutectic surface fraction over composition from $\mu-\mathrm{XCT}$ (solid) measurements and RVE-FE (dashed) model.

\subsection{Eutectic Thickness: SEM E $\mu$-XCT}

The eutectic thickness was evaluated from SEM cross-sections for Sn- 20, 30, 35 and 47 wt.\% Bi alloys for comparison with 3D measurement. The cross-sections are illustrated in Figure 12, where Figure 12a-d shows the microstructure of the 20, 30 and 47 wt.\% Bi alloys, respectively. The white domains in Figure $12 \mathrm{a}-\mathrm{d}$ show the eutectic phase, embedded in gray primary phase. Secondary precipitates of Bi can be seen in the primary phase, which form due to a reduced solubility of $\mathrm{Bi}$ in $\beta-\mathrm{Sn}$ at room temperature. The corresponding 
local thickness map of the reference samples is illustrated in Figure 13a-d. In case of the Sn-Bi system, the eutectic thickness provides a close estimate of the liquid film above the solidus temperature. The liquid film thickness defines the tensile strength of the alloy in the last stage of solidification [34] and is a determining factor for the formation of solidification cracks. The hot tearing criteria reviewed by Eskin et al. [34] show an inverse relation of liquid film thickness and strength. Therefore, the Sn-20 wt.\% Bi alloy is expected to provide the highest mechanical strength in the semi-solid configuration among the studied alloys.

(a)

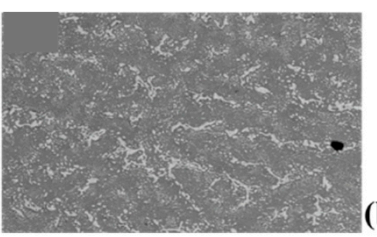

(c)

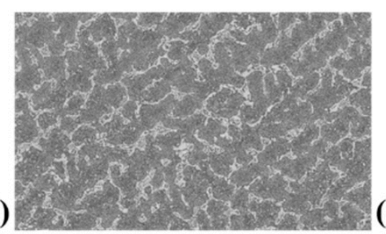

(b)

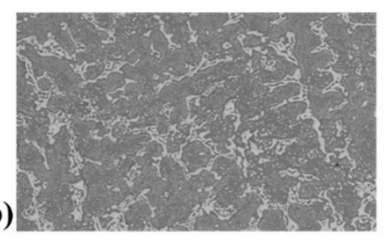

(d)

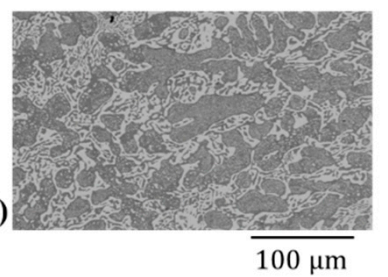

Figure 12. SEM cross-sections of Sn-Bi alloys (a) Sn-20 wt.\% Bi (b) Sn-30 wt. \% Bi (c) Sn-35 wt.\% Bi (d) Sn-47 wt.\% Bi. Scale bar with $100 \mu \mathrm{m}$ applies to all images.

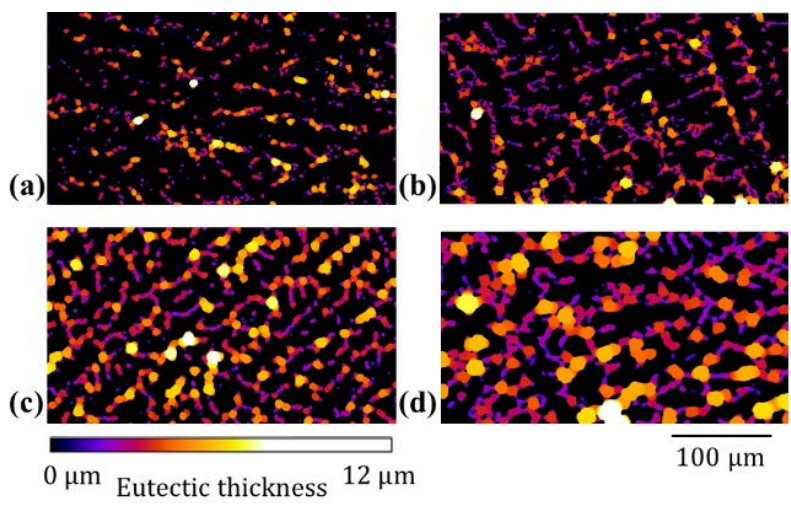

Figure 13. Local eutectic thickness map of Sn-Bi alloys (a) Sn-20 wt.\% Bi (b) Sn-30 wt.\% Bi (c) Sn-35 wt.\% Bi (d) Sn- 47 wt.\% Bi. The color spectrum defines the eutectic thickness, scale bar applies on all images.

A comparison of $\mu$-XCT and SEM measurements is given in Figure 14. A good correlation between both imaging techniques is observed over alloy compositions. It shows that SEM cross-sections provide a good estimate for the local phase thickness. Nevertheless, 2D measurements give a lower bound estimate for the actual local thickness. This is shown in Figure 14 with SEM measurements being close to lower values of $\mu$-XCT measurements. A possible size-dependence of the eutectic thickness on VOI was investigated with results given in Figure A5. 


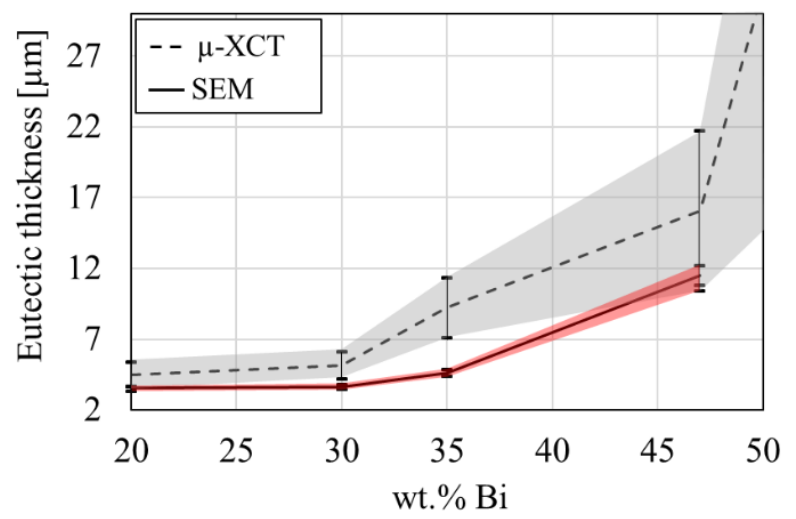

Figure 14. Comparison of the image analyzed eutectic thickness obtained from the $\mu-X C T$ data and SEM data as a function of alloy composition. Error bars indicate the standard deviation of eutectic thickness.

\subsection{Morphology Classification}

A volumetric classification is given in Figure 15, which shows the volume fraction of each morphologic class for all alloy composition. Detailed values can be found in Appendix D in Table A2. The Sn-20 wt.\% Bi alloy is composed of complex, equiaxed, rod and sheet areas, where $40 \%$ of the microstructure is composed of equiaxed domains. The $\mathrm{Sn}-$ $30 \mathrm{wt} . \% \mathrm{Bi}$ and $\mathrm{Sn}-35 \mathrm{wt} . \%$ Bi alloys reveal complex microstructures due to the large eutectic and primary networks. In Table A2, insignificant fractions of equiaxed and rod-shaped domains are given. The $\mathrm{Sn}-47 \mathrm{wt} . \% \mathrm{Bi}$ and $\mathrm{Sn}-58 \mathrm{wt} . \% \mathrm{Bi}$ alloys are composed of equiaxed and complex domains, where the equiaxed areas have a minor volume fraction of $7 \%$ and $26 \%$. Overall, the relative volume fractions in Figure 15 reveal similar morphologies among some of the investigated alloys. Three categories are suggested to group alloys with similar features. The Sn-20 wt.\% Bi alloy represents a "mixed" microstructure with significant amounts of complex, equiaxed, rod and sheet domains. The Sn-30 wt.\% Bi and Sn-35 wt.\% Bi alloys show a "complex-dominated" structure with negligible contributions of equiaxedand rod-shaped areas. Furthermore, the Sn- $47 \mathrm{wt} . \%$ Bi and Sn- $58 \mathrm{wt} . \%$ Bi alloys are summarized as "complex-equiaxed", where the microstructure is dominated by complex areas with a significant presence of equiaxed domains. The data in Figure 15 suggests that alloys with eutectic phase fraction between 30 and $60 \%$ are complex dominated due to the formation of a fine network of eutectic phase. The dendritic primary phase for alloys with 47 and $58 \mathrm{wt} . \%$ Bi leads to a fraction of equiaxed domains of $7 \%$ and $26 \%$.

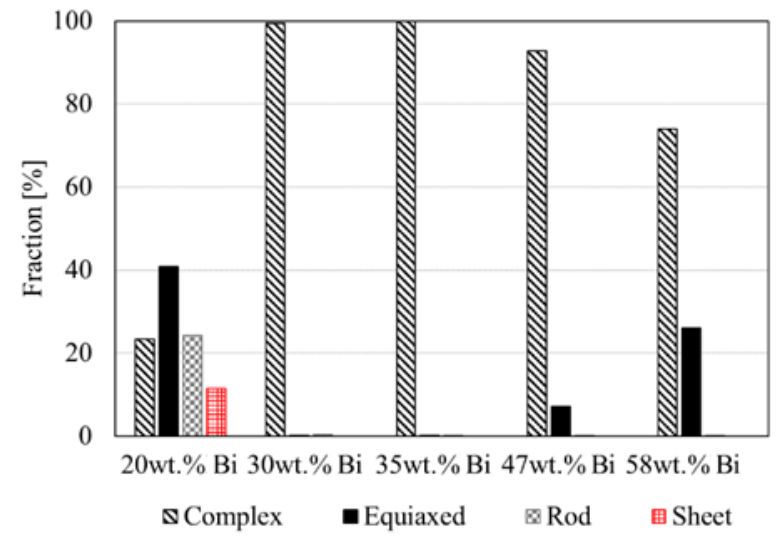

Figure 15. Volume fractions of morphology classes in Sn-Bi alloys obtained from segmented $\mu$-XCT data. 


\subsection{Morphology and Elastic Anisotropy}

To investigate a possible correlation among geometric and elastic anisotropy, Young's moduli were computed with the RVE-FE models. Figure 16 shows the elastic response over composition, where Figure 16a shows the moduli in each spatial direction of the unit cell. Figure $16 \mathrm{~b}$ shows the elastic $D A_{\mathrm{el}}$ computed according to Equation (5). The Sn-20 wt.\% Bi alloy shows the most pronounced orientation dependency, with a 1.4 GPa higher modulus in z-direction. This agrees with the equivalent ellipsoid stretched in $\mathrm{z}$ direction in Figure A7. The remaining alloys show a negligible orientation-dependence. The elastic $D A_{\mathrm{el}}$ parameter in Figure 16b indicates an isotropic characteristic for all alloys. The highest anisotropy is found for the $\mathrm{Sn}-20 \mathrm{wt} . \% \mathrm{Bi}$ alloy with $D A_{\mathrm{el}}=0.03$. The similar elastic constants of primary and eutectic phase reduce the geometric anisotropy found in $\mu$-XCT Data shown in Figure 9. Furthermore, it is important to discuss the effect of crystal anisotropy on the elastic properties. In principle, single grains or grain boundaries are hardly detected through lab-scale $\mu$-XCT. Nevertheless, a similar approach was reported by Wijaya et al. [51], where the local crystal orientation of the microstructure was neglected and good correlation of experimental and numerical results of elastic properties was achieved. However, in case of solder joints, the local crystal anisotropy becomes a determining factor for solder joint reliability [52]. The body-centered tetragonal crystal structure causes an elastic and thermal expansion misfit, where large-angle grain boundaries act as damage initiation sites.
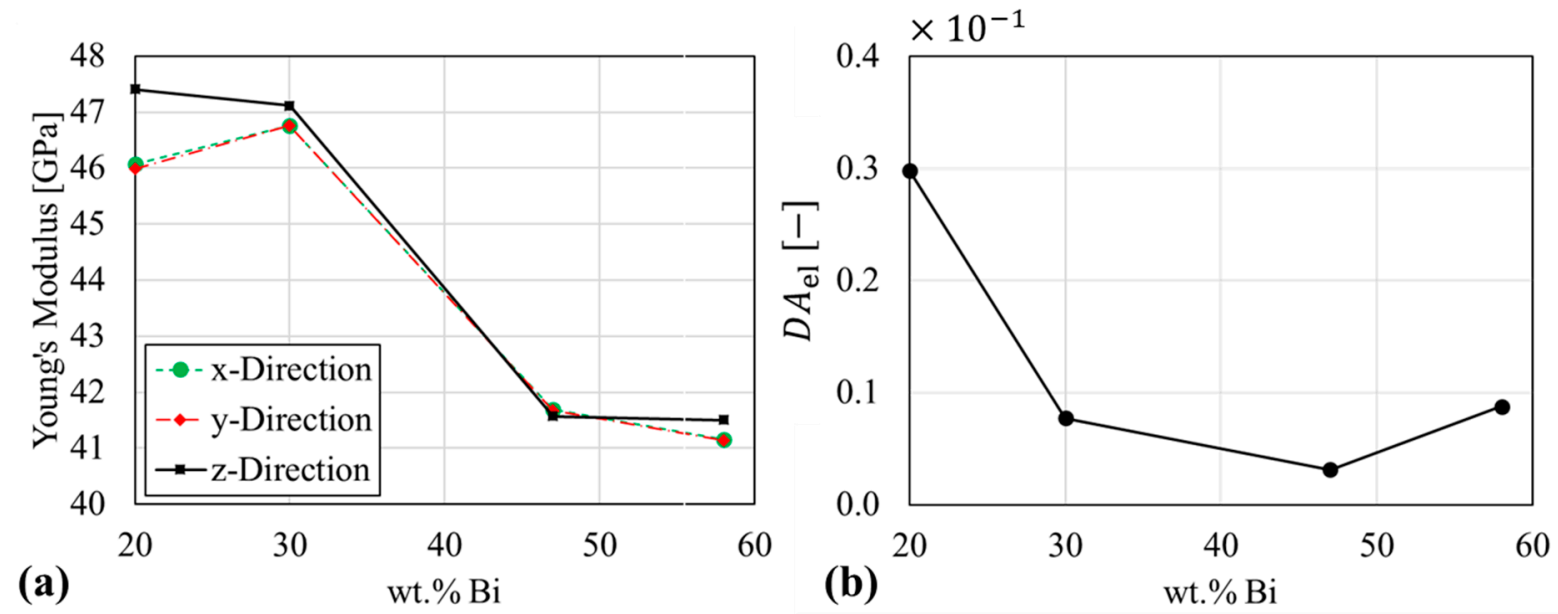

Figure 16. Evaluation of calculated elastic anisotropy from RVE-FEM models (a) Young's moduli from unidirectional tensile deformation (b) degree of anisotropy from Young's modulus.

\subsection{Semi-Solid Shear Strength}

The microstructural and morphology descriptors reported in the present work allow a discussion of several mechanical properties in the semi-solid state, with the eutectic phase still being liquid $[35,36]$. Under these conditions, the residual strength of the solder joint is an important measure to estimate tolerable external forces. The shear strength of $\mathrm{Sn}-\mathrm{Pb}$ semi-solids of varying microstructure was studied by Martin et al. [53], which is used for a comparative discussion due to its close similarity to the Sn-Bi system. The authors reported a morphology-dependence of shear strength, where equiaxed microstructures showed lower values of about $1 / 10$ compared to those for dendritic microstructures. The liquid fraction also influenced the shear strength in the semi-solid state, with values ranging from $3 \mathrm{MPa}$ at liquid fraction of $\phi_{\mathrm{L}}=20 \%$ to $1.2 \mathrm{MPa}$ at $\phi_{\mathrm{L}}=37 \%$. Assuming a condition close to the solidus temperature of $T_{\mathrm{S}}=138^{\circ} \mathrm{C}$. the liquid fraction of Sn-Bi alloys is equal to the volume fraction of eutectic, where measured values are given in Table 3. Therefore, one can conclude that the expected shear strength during healing of the Sn-20 wt.\% Bi alloy will be $>3 \mathrm{MPa}$, as a result of the presences of the solid skeleton of $\beta$-Sn illustrated in Figure 4a. The remaining alloys with $30 \mathrm{wt} . \%$ to $58 \mathrm{wt} . \%$ Bi are likely to have a shear 
strength $<1 \mathrm{MPa}$ in comparison with [53]. The shear strengthening effect of dendritic microstructures reported by Martin et al. [53] in case of the Sn-58 wt.\% Bi is most likely overcompensated by the high liquid fraction of $\phi_{\mathrm{L}}=94.7 \%$. Furthermore, the presence of a liquid film network shown in Figure $3 \mathrm{~b}-\mathrm{d}$ is an additional limitation of semi-solid strength. The above analysis provides an estimate for choosing the handling conditions of solder joints during liquid-assisted healing.

Table 3. Liquid fraction at solidus temperature over solder composition.

\begin{tabular}{lc}
\hline Composition & $\phi_{\mathrm{L}}$ at $\boldsymbol{T}_{\mathrm{S}}$ \\
\hline Sn-20 wt.\% Bi & $17.1 \%$ \\
Sn-30wt.\% Bi & $31.8 \%$ \\
Sn-35 wt. $\%$ Bi & $59.4 \%$ \\
Sn-47 wt. $\%$ Bi & $70.8 \%$ \\
Sn-58 wt. $\%$ Bi & $94.7 \%$ \\
\hline
\end{tabular}

\subsection{Semi-Solid Uniaxial Compression}

Theoretical considerations of liquid-assisted healing reported in References. [35,36] suggest that external compressive deformation is a driving force for liquid-assisted healing. This effect is limited by the tendency of void formation under semi-solid compression, which has been investigated for Al-Cu alloys [54-56]. The eutectic character of this alloy system offers enough similarity with Sn-Bi solders for qualitative comparison. Kareh et al. [55] studied void formation in globular-equiaxed microstructures under variation of liquid fraction. The alloys deformed similarly to a cohesion-less granular material and showed a varying tendency of void formation under uniaxial compression, which was associated with shear-induced dilation of the microstructure. A critical liquid fraction of $\phi_{\mathrm{S}}=37.6 \%$ was found above which void formation was fully inhibited. A minimal liquid channel thickness is required to compensate dilation and accommodate grain movement. In case of interacting solid grains, which is likely when the liquid film thickness drops below the minimal required value, void formation is observed. These results suggest that Sn-Bi alloys with $>30 \mathrm{wt} . \%$ Bi provide the required liquid film thickness to be insensitive to void formation during compression. The work of Cai et al. [56] supports this suggestions, as void shrinkage under compressive strains of $\epsilon<1.2 \%$ in the semi-solid was observed in alloys with $\phi_{\mathrm{S}}=30 \%$. Further uniaxial compression, however, leads to nucleation and growth of voids as soon as the liquid film thickness shrinks, inducing local tensile stresses and inhibiting liquid feeding. The microstructural data of Sn-Bi alloys, therefore, suggest a varying degree of maximum compression to be applied until void nucleation appears in the liquid. The critical value of $\phi_{\mathrm{S}}$ reported by Kareh et al. [55] is fulfilled for $\mathrm{Sn}$ alloys with 35,47 and $58 \mathrm{wt} . \% \mathrm{Bi}$. It is theorized that the Sn-35 wt.\% Bi alloy with an average liquid film thickness of $9.2 \mu \mathrm{m}$ will tolerate less uniaxial compression than the Sn- $47 \mathrm{wt} . \%$ and Sn$58 \mathrm{wt} . \%$ Bi alloys with $16 \mu \mathrm{m}$ and $73 \mu \mathrm{m}$ liquid thickness, respectively, due to early closing of the liquid film. Further semi-solid compression experiments on these alloys could reveal the degree of tolerable deformation and provide a link between microstructural features and semi-solid void formation. In particular, the evolution of morphology parameters, such as, $\Omega_{3}, E, F$ with respect to semi-solid deformation, can identify the 'safe' and the 'damage-creating' conditions.

\subsection{Semi-Solid Permeability}

The theoretical considerations of liquid-assisted healing in References. [35,36] discussed the role of local material transport for void healing. It was mentioned that the local resistance against material transport will lead to a deviation of the theoretical healing 
efficiency. The Carman-Kozeny relation [57] is used to describe the permeability, $K$. This quantity provides an estimate for resistance against liquid flow as

$$
K=\frac{\left(1-f_{\mathrm{s}}\right)^{3}}{k_{\mathrm{c}} S_{\mathrm{V}}^{2} f_{\mathrm{s}}^{2}}
$$

with $f_{\mathrm{s}}$ being the solid fraction, $k_{\mathrm{c}}$ being a dimensional constant ( 3 for dendritic and 5 for equiaxed structures) and $S_{\mathrm{v}}$ the surface fraction. The dimensionless permeability indicates the required pressure gradient for fluid flow and is given in Figure 17 from measured values of $f_{\mathrm{s}}$ and $S_{\mathrm{v}}$ according to Equation (9). The pressure gradient and fluid flow was investigated by 5 .

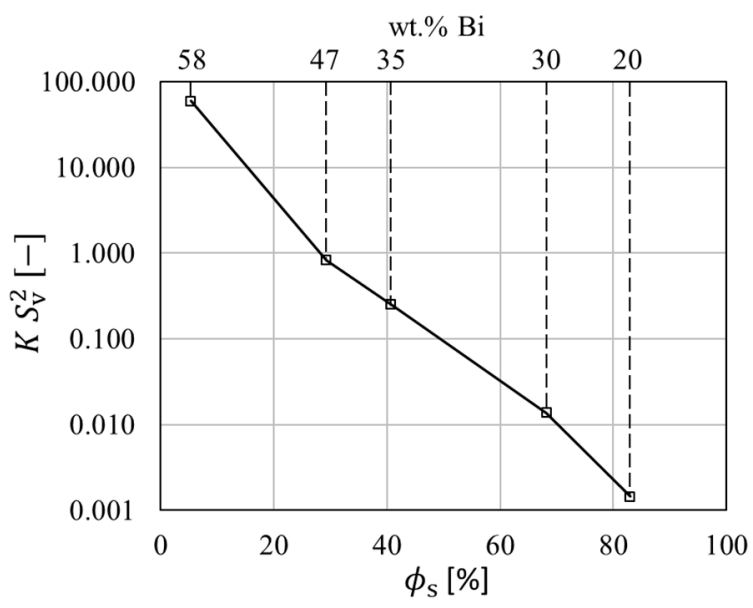

Figure 17. Dimensionless permeability over solid fraction (just before the final formation of the eutectic fraction) and Sn-Bi alloy composition, calculated from $\mu$-XCT measurements.

\subsection{Implications for Liquid Phase Healing}

The discussion of shear strength, uniaxial compression and permeability in the semisolid state provides necessary criteria for liquid phase healing. The presence of a liquid phase network is required to increase the microstructural permeability and to allow material transport for defect filling, which is fulfilled for the investigated solders except the Sn-20 wt.\% Bi alloy. Furthermore, alloys with 35, 47 and 58 wt.\% Bi provide a liquid fraction larger than the critical value of $38 \%$ reported by Kareh et al. [55] to prevent formation of porosities during compression. These alloys require a load free condition during healing, due to the low expected shear strength in the semi-solid state. Therefore, solders of 35,47 and $58 \mathrm{wt} . \%$ Bi show the highest potential of liquid phase healing in absence of external loads.

\section{Conclusions}

This work presents a thorough microstructural analysis of $\mu$-XCT data of five Sn alloys with varying Bi content. The following outcomes are reported:

1. Eutectic phase fractions measured with $\mu$-XCT showed good correlation with expected values from CALPHAD calculations.

2. The Sn-20 wt.\% Bi alloy show fragmented domains of eutectic embedded in primary phase. The Sn-35 wt.\% Bi alloy reveals interpenetrating primary and eutectic phase, which is reflected by the highest phase boundary area fraction. The Sn-58 wt.\% Bi, despite its high eutectic phase fraction, showed a connected dendritic network of primary phase.

3. The morphology analysis shows microstructural similarities of the investigated alloys. The $\mathrm{Sn}-20 \mathrm{wt} . \%$ Bi alloy is composed of four geometric features and its microstructure is categorized as "mixed". The alloys with $30 \mathrm{wt} . \%$ and $35 \mathrm{wt} . \% \mathrm{Bi}$ are composed of 
mainly "complex-shaped" areas. The alloys of near-eutectic composition, Sn- $47 \mathrm{wt} . \%$ $\mathrm{Bi}$ and $58 \mathrm{wt} . \% \mathrm{Bi}$, constitute from "complex" and "equiaxed" domains.

4. The RVE-FE simulations showed an elastically isotropic response, despite significant spatial orientation of the microstructures. The similar elastic properties of primary and eutectic phase reduce the impact of geometric anisotropy. Results are in agreement with linear and inverse rule of mixture.

Finally, it can be concluded that the analysis of liquid phase fraction, liquid film thickness and permeability suggests that among the investigated Sn-Bi alloys, those with a Bi content between 35 and $58 \mathrm{wt} . \%$ have the highest potential for liquid phase healing. The low mechanical strength in this configuration requires a load free condition during healing.

Author Contributions: Conceptualization, G.S., W.E., S.v.d.Z.; methodology, G.S., W.E., J.R.; software, G.S., J.R.; validation, G.S., R.B. and W.E.; formal analysis, G.S.; investigation, G.S., J.R.; resources, E.K. (Elke Kraker), D.K.; writing—original draft preparation, G.S., J.R.; writing—review and editing, W.E., E.K. (Elke Kraker), R.B., E.K. (Ernst Kozeschnik), S.v.d.Z., D.K.; visualization, G.S., J.R.; supervision, W.E., E.K. (Ernst Kozeschnik); project administration, E.K. (Elke Kraker), D.K.; funding acquisition, E.K. (Elke Kraker), D.K. All authors have read and agreed to the published version of the manuscript.

Funding: This research was funded by Austrian Research Promotion Agency (FFG), grant number 864808 .

Institutional Review Board Statement: Not applicable.

Informed Consent Statement: Not applicable.

Data Availability Statement: Data sharing is not applicable to this article.

Acknowledgments: Financial support by the Austrian Federal Government (in particular from Federal Ministry for Transport, Innovation and Technology) represented by the Austrian Research Promotion Agency (FFG), within the framework of the "24. Ausschreibung Produktion der Zukunft, nationale Projekte" Programme (project number: 864808 project name: SOLARIS) is gratefully acknowledged. Sybrand van der Zwaag acknowledges support from the Dutch Innovative Research Program Self Healing Materials (IOP-SHM).

Conflicts of Interest: The authors declare no conflict of interest.

\section{Appendix A. Phase Diagram \& Scheil Analysis}

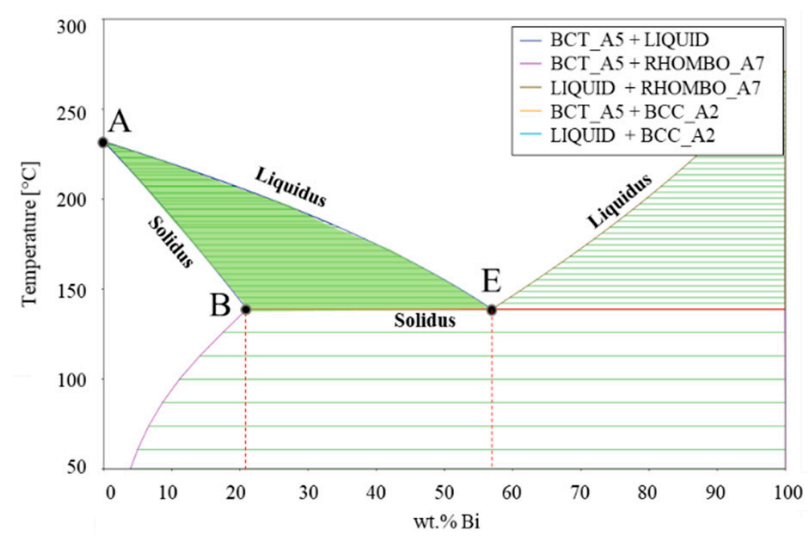

Figure A1. Sn-Bi binary phase diagram. 

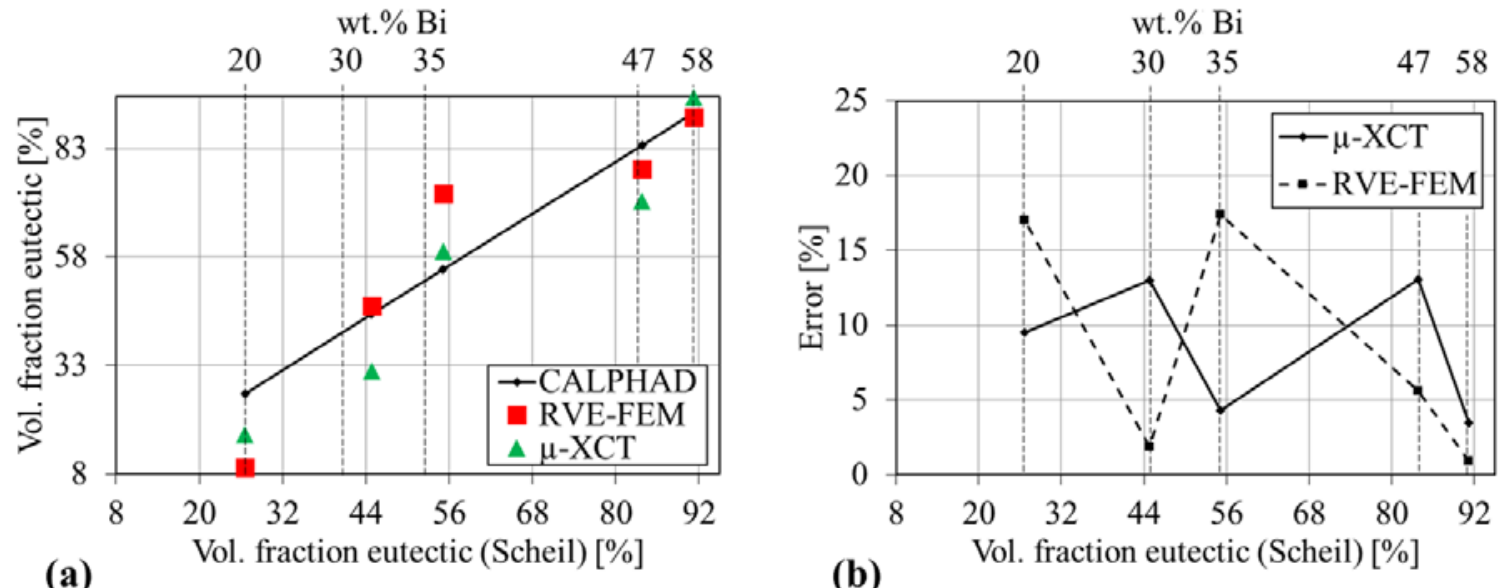

Figure A2. Eutectic volume fraction from CALPHAD calculations, $\mu$-XCT imaging and the RVE-FE model (a) eutectic volume fraction over composition (b) relative error of $\mu-X C T$ data and RVE-FE model based on Scheil CALPHAD calculations over composition.

\section{Appendix B. Volume of Interest Variations}

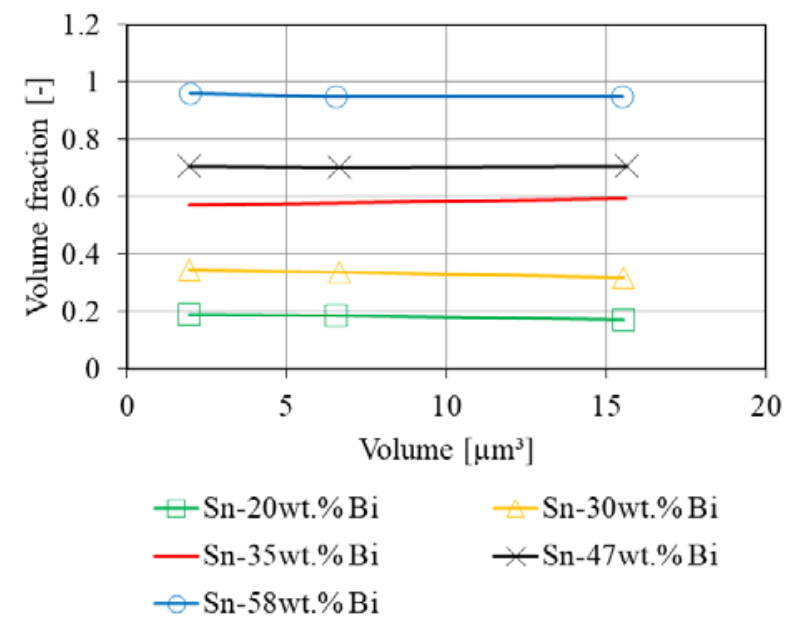

Figure A3. Volume fraction over variation of VOI and alloy composition.

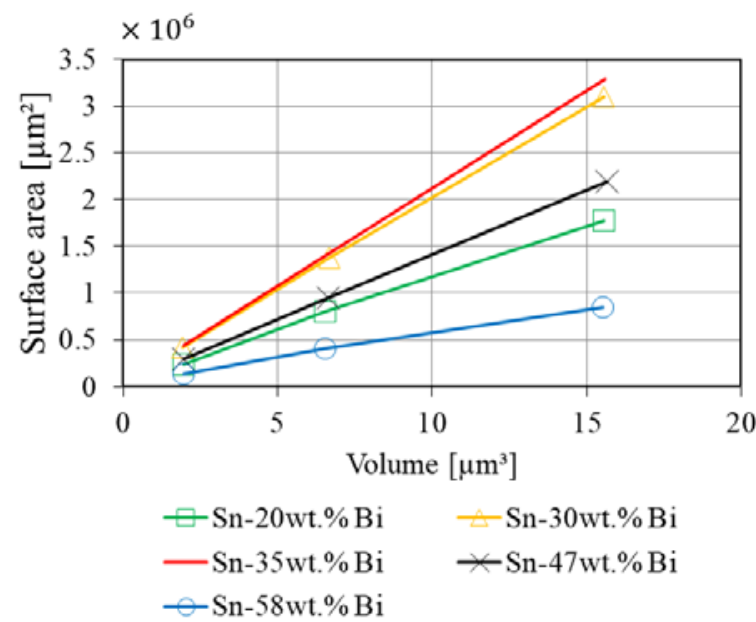

Figure A4. Eutectic surface area over variation of VOI and alloy composition. 


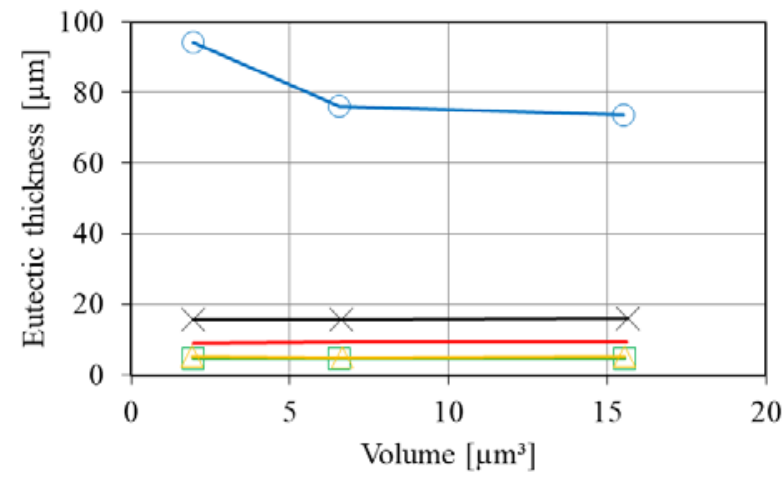

$$
\begin{aligned}
& \square \text { Sn-20wt.\% Bi } \quad \longleftarrow \text { Sn-30wt.\% Bi } \\
& - \text { Sn-35wt.\% Bi } \quad \leftarrow \text { Sn-47wt.\% Bi } \\
& \smile \text { Sn-58wt.\% Bi }
\end{aligned}
$$

Figure A5. Eutectic thickness over variation of VOI and alloy composition.

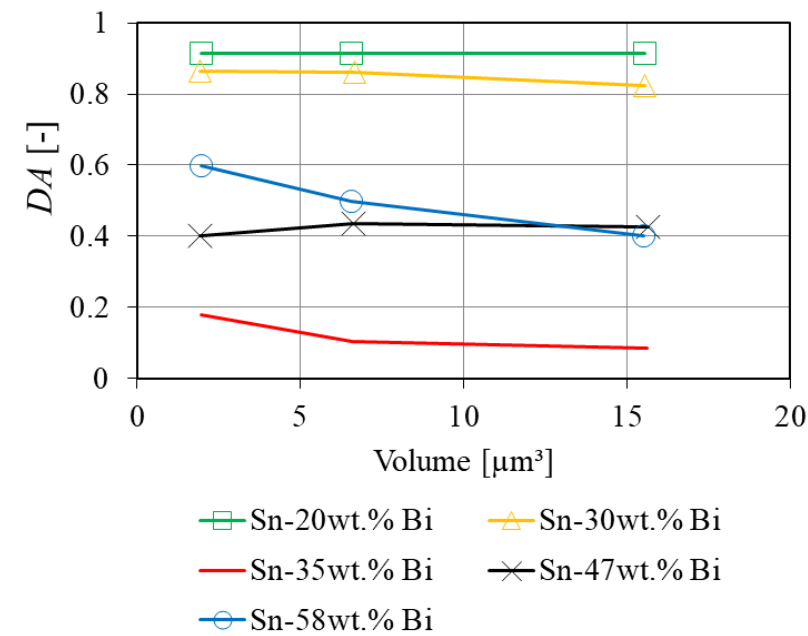

Figure A6. Degree of anisotropy over variation of VOI and alloy composition.

\section{Appendix C. Ellipsoid Fit}

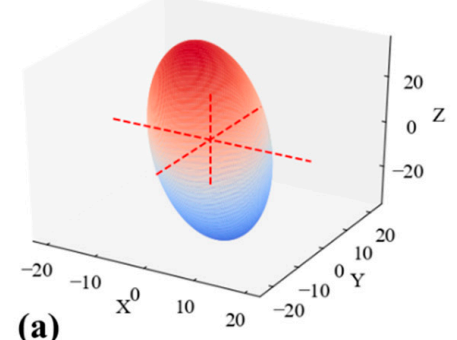

(a)

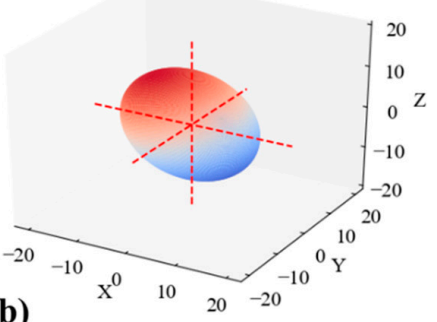

(b)

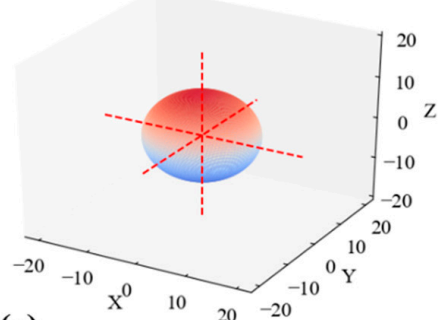

(c)

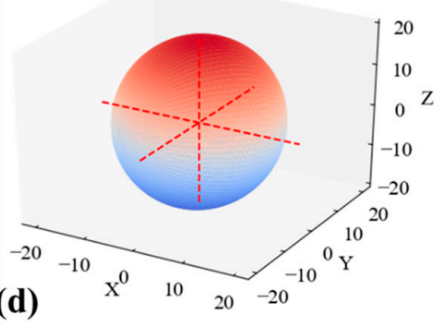

(e)

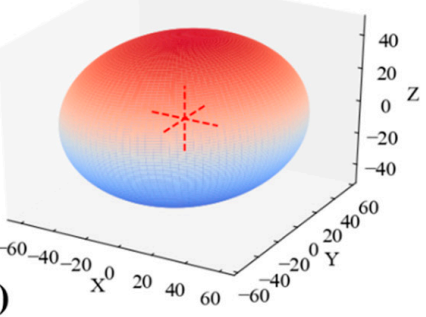

Figure A7. Ellipsoids according to Table A1 of (a) Sn-20 wt.\% Bi (b) Sn-30 wt.\% Bi (c) Sn-35 wt.\% Bi (d) Sn-47 wt.\% Bi (e) Sn-58 wt.\% Bi. 
Table A1. Degree of anisotropy, eigenvectors $m_{i j}$ and eigenvalues $\lambda_{i}$ of ellipsoid fit.

\begin{tabular}{cccccccccccccc}
\hline wt.\% Bi & DA & $m_{\mathbf{1 1}}$ & $\boldsymbol{m}_{\mathbf{1 2}}$ & $\boldsymbol{m}_{\mathbf{1 3}}$ & $\boldsymbol{m}_{\mathbf{2 1}}$ & $\boldsymbol{m}_{\mathbf{2 2}}$ & $\boldsymbol{m}_{\mathbf{2 3}}$ & $\boldsymbol{m}_{\mathbf{3 1}}$ & $\boldsymbol{m}_{\mathbf{3 2}}$ & $\boldsymbol{m}_{\mathbf{3 3}}$ & $\boldsymbol{\lambda}_{\mathbf{1}}$ & $\boldsymbol{\lambda}_{\mathbf{2}}$ & $\boldsymbol{\lambda}_{\mathbf{3}}$ \\
\hline 20 & 0.914 & 0.159 & -0.119 & -0.980 & 0.415 & -0.893 & 0.176 & 0.896 & 0.434 & 0.093 & 0.0008 & 0.0018 & 0.0088 \\
30 & 0.825 & -0.317 & -0.776 & 0.545 & -0.339 & 0.629 & 0.700 & 0.886 & -0.037 & 0.463 & 0.0036 & 0.0067 & 0.0208 \\
35 & 0.085 & 0.690 & 0.676 & -0.259 & 0.660 & 0.734 & -0.160 & -0.299 & -0.061 & 0.952 & 0.0089 & 0.0090 & 0.0097 \\
47 & 0.425 & 0.061 & 0.059 & 0.996 & 0.808 & 0.589 & -0.014 & 0.586 & 0.806 & 0.083 & 0.0025 & 0.0038 & 0.0044 \\
58 & 0.401 & 0.824 & 0.565 & 0.050 & 0.564 & -0.825 & 0.032 & 0.059 & 0.002 & -0.998 & 0.0002 & 0.0004 & 0.0004 \\
\hline
\end{tabular}

\section{Appendix D. Volume Fractions of Morphologic Classes}

Table A2. Volume fraction of morphologic classes.

\begin{tabular}{ccccc}
\hline wt. $\%$ Bi & Equiaxed & Rod & Sheet & Complex \\
\hline 58 & 26.034 & 0.033 & 0.0 & 74.0 \\
47 & 7.076 & 0.108 & 0.0 & 92.8 \\
35 & 0.065 & 0.002 & 0.0 & 99.9 \\
30 & 0.244 & 0.271 & 0.0 & 99.5 \\
20 & 40.859 & 24.171 & 11.5 & 23.4 \\
\hline
\end{tabular}

\section{References}

1. Cheng, F.; Gao, F.; Zhang, J.; Jin, W.; Xiao, X. Tensile properties and wettability of SAC0307 and SAC105 low Ag lead-free solder alloys. J. Mater. Sci. 2011, 46, 3424-3429. [CrossRef]

2. Wang, F.; Chen, H.; Huang, Y.; Liu, L.; Zhang, Z. Recent progress on the development of Sn-Bi based low-temperature Pb-free solders. J. Mater. Sci. Mater. Electron. 2019, 30, 3222-3243. [CrossRef]

3. Shalaby, R.M. Effect of silver and indium addition on mechanical properties and indentation creep behavior of rapidly solidified Bi-Sn based lead-free solder alloys. Mater. Sci. Eng. A 2013, 560, 86-95. [CrossRef]

4. Shen, J.; Pu, Y.; Yin, H.; Luo, D.; Chen, J. Effects of minor $\mathrm{Cu}$ and $\mathrm{Zn}$ additions on the thermal, microstructure and tensile properties of Sn-Bi-based solder alloys. J. Alloys Compd. 2014, 614, 63-70. [CrossRef]

5. Yang, C.H.; Zhou, S.; Lin, S.K.; Nishikawa, H. A computational thermodynamics-assisted development of Sn-Bi-In-Ga quaternary alloys as low-temperature Pb-free solders. Materials 2019, 12, 631. [CrossRef]

6. Ren, G.; Wilding, I.J.; Collins, M.N. Alloying influences on low melt temperature SnZn and SnBi solder alloys for electronic interconnections. J. Alloys Compd. 2016, 665, 251-260. [CrossRef]

7. Collins, M.N.; Punch, J.; Coyle, R.; Reid, M.; Popowich, R.; Read, P.; Fleming, D. Thermal Fatigue and Failure Analysis of SnAgCu Solder Alloys with Minor Pb Additions. IEEE Trans. Compon. Packag. Manuf. Technol. 2011, 1, 1594-1600. [CrossRef]

8. Wu, X.; Wu, J.; Wang, X.; Yang, J.; Xia, M.; Liu, B. Effect of in addition on microstructure and mechanical properties of Sn-40Bi alloys. J. Mater. Sci. 2020, 55, 3092-3106. [CrossRef]

9. Silva, B.L.; Xavier, M.G.C.; Garcia, A.; Spinelli, J.E. Cu and Ag additions affecting the solidification microstructure and tensile properties of Sn-Bi lead-free solder alloys. Mater. Sci. Eng. A 2017, 705, 325-334. [CrossRef]

10. Ren, G.; Collins, M.N. Improved reliability and mechanical performance of Ag microalloyed Sn58Bi solder alloys. Metals 2019, 9, 462. [CrossRef]

11. Covre, T.O.R.; Da, E.; Silva, B.L.; Spinelli, E.; Garcia, A. Effects of Solidification Thermal Parameters on Microstructure and Mechanical Properties of Sn-Bi Solder Alloys. J. Electron. Mater. 2017, 46, 1754-1769. [CrossRef]

12. El-Daly, A.A.; Ibrahiem, A.A.; Hammad, A.E. Impact of permanent magnet stirring on dendrite growth and elastic properties of Sn-Bi alloys revealed by pulse echo overlap method. J. Alloys Compd. 2018, 767, 464-473. [CrossRef]

13. Silva, B.L.; Reinhart, G.; Nguyen-Thi, H.; Mangelinck-Noël, N.; Garcia, A.; Spinelli, J.E. Microstructural development and mechanical properties of a near-eutectic directionally solidified Sn-Bi solder alloy. Mater. Charact. 2015, 107, 43-53. [CrossRef]

14. Silva, B.L.; Garcia, A.; Spinelli, J.E. Complex eutectic growth and Bi precipitation in ternary Sn-Bi-Cu and Sn-Bi-Ag alloys. J. Alloys Compd. 2017, 691, 600-605. [CrossRef]

15. Kamioka, H. Temperature variations of elastic moduli up to eutectic temperature in tin-bismuth alloys. Jpn. J. Appl. Phys. 1983, 22, 1805-1809. [CrossRef]

16. Kamioka, H. Behavior of Tin-Bismuth Alloys near Melting Point Found by Measurement of Sound Velocity. J. Phys. Soc. Jpn. 1984, 53, 1349-1355. [CrossRef]

17. Shen, L.; Septiwerdani, P.; Chen, Z. Elastic modulus, hardness and creep performance of SnBi alloys using nanoindentation. Mater. Sci. Eng. A 2012, 558, 253-258. [CrossRef]

18. Maire, E.; Withers, P.J. Quantitative X-ray tomography. Int. Mater. Rev. 2014, 59, 1-43. [CrossRef] 
19. Jiang, L.; Chawla, N.; Pacheco, M.; Noveski, V. Three-dimensional (3D) microstructural characterization and quantification of reflow porosity in Sn-rich alloy/copper joints by X-ray tomography. Mater. Charact. 2011, 62, 970-975. [CrossRef]

20. Rauer, M.; Volkert, A.; Schreck, T.; Härter, S.; Kaloudis, M. Computed-tomography-based analysis of voids in SnBi57Ag1 solder joints and their influence on the reliability. J. Fail. Anal. Prev. 2014, 14, 272-281. [CrossRef]

21. Shi, L.; Mei, Y.; Chen, G.; Chen, X. In situ X-ray observation and simulation of ratcheting-fatigue interactions in solder joints. Electron. Mater. Lett. 2017, 13, 97-106. [CrossRef]

22. Yazzie, K.E.; Williams, J.J.; Phillips, N.C.; De Carlo, F.; Chawla, N. Multiscale microstructural characterization of Sn-rich alloys by three dimensional (3D) X-ray synchrotron tomography and focused ion beam (FIB) tomography. Mater. Charact. 2012, 70, 33-41. [CrossRef]

23. Kirubanandham, A.; Lujan-Regalado, I.; Vallabhaneni, R.; Chawla, N. Three Dimensional Characterization of Tin Crystallography and Cu6Sn5 Intermetallics in Solder Joints by Multiscale Tomography. JOM 2016, 68, 2879-2887. [CrossRef]

24. Kaira, C.S.; Mayer, C.R.; De Andrade, V.; De Carlo, F.; Chawla, N. Nanoscale three-dimensional microstructural characterization of an Sn-rich solder alloy using high-resolution transmission X-ray microscopy (TXM). Microsc. Microanal. 2016, 22, 808-813. [CrossRef]

25. Mertens, J.C.E.; Williams, J.J.; Chawla, N. A Study of Pb-Rich Dendrites in a Near-Eutectic 63Sn-37Pb Solder Microstructure via Laboratory-Scale Micro X-ray Computed Tomography (1 XCT). J. Electron. Mater. 2014, 43, 4442-4456. [CrossRef]

26. Maleki, M.; Cugnoni, J.; Botsis, J. Isothermal ageing of SnAgCu solder alloys: Three-dimensional morphometry analysis of microstructural evolution and its effects on mechanical response. J. Electron. Mater. 2014, 43, 1026-1042. [CrossRef]

27. Chang, Y.; Cheng, Y.; Xu, F.; Helfen, L.; Tian, T.; Di, M.; Chen, C.; Tu, K.; Baumbach, T. Study of electromigration-induced formation of discrete voids in flip-chip solder joints by in-situ 3D laminography observation and fi nite-element modeling. Acta Mater. 2016, 117, 100-110. [CrossRef]

28. Okereke, M.I.; Ling, Y. A computational investigation of the effect of three-dimensional void morphology on the thermal resistance of solder thermal interface materials. Appl. Therm. Eng. 2018, 142, 346-360. [CrossRef]

29. Maleki, M.; Cugnoni, J.; Botsis, J. Multi-scale modeling of elasto-plastic response of SnAgCu lead-free solder alloys at different ageing conditions: Effect of microstructure evolution, particle size effects and interfacial failure. Mater. Sci. Eng. A 2016, 661, 132-144. [CrossRef]

30. Sistaninia, M.; Phillion, A.B.; Drezet, J.M.; Rappaz, M. Three-dimensional granular model of semi-solid metallic alloys undergoing solidification: Fluid flow and localization of feeding. Acta Mater. 2012, 60, 3902-3911. [CrossRef]

31. Kopp, R.; Choi, J.; Neudenberger, D. Simple compression test and simulation of an $\mathrm{Sn}-15 \%$ Pb alloy in the semi-solid state. J. Mater. Process. Technol. 2003, 135, 317-323. [CrossRef]

32. Sheykh-jaberi, F.; Cockcroft, S.L.; Maijer, D.M.; Phillion, A.B. Meso-scale modelling of semi-solid deformation in aluminum foundry alloys: Effects of feeding and microstructure on hot tearing susceptibility. J. Mater. Process. Technol. 2020, $279,116551$. [CrossRef]

33. Sistaninia, M.; Terzi, S.; Phillion, A.B.; Drezet, J.M.; Rappaz, M. 3-D granular modeling and in situ X-ray tomographic imaging: A comparative study of hot tearing formation and semi-solid deformation in Al-Cu alloys. Acta Mater. 2013, 61, 3831-3841. [CrossRef]

34. Eskin, D.G.; Suyitno; Katgerman, L. Mechanical properties in the semi-solid state and hot tearing of aluminium alloys. Prog. Mater. Sci. 2004, 49, 629-711. [CrossRef]

35. Siroky, G.; Kraker, E.; Kieslinger, D.; Kozeschnik, E.; Ecker, W. Micromechanics-based damage model for liquid-assisted healing. Int. J. Damage Mech. 2020, 0, 1-22. [CrossRef]

36. Siroky, G.; Melinc, D.; Magnien, J.; Kozeschnik, E.; Kieslinger, D.; Kraker, E.; Ecker, W. Healing solders: A numerical investigation of damage-healing experimentse. In Proceedings of the 2020 21st International Conference on Thermal, Mechanical and MultiPhysics Simulation and Experiments in Microelectronics and Microsystems (EuroSimE), Cracow, Poland, 5-8 July 2020; pp. $1-7$.

37. Chawla, N.; Sidhu, R.S. Microstructure-based modeling of deformation in Sn-rich (Pb-free) solder alloys. J. Mater. Sci. Mater. Electron. 2007, 18, 175-189. [CrossRef]

38. Harrigan, T.P.; Mann, R.W. Characterization of microstructural anisotropy in cancellous bone using a second rank tensor. J. Mater. Sci. 1985, 19, 761-767. [CrossRef]

39. Fang, H.; Versteylen, C.D.; Zhang, S.; Yang, Y.; Cloetens, P.; Ngan-tillard, D. Autonomous filling of creep cavities in Fe-Au alloys studied by synchrotron X-ray nano-tomography. Acta Mater. 2016, 121, 352-364. [CrossRef]

40. Wadell, H. Volume, Shape, and Roundness of Quartz Particles. J. Geol. 1935, 43. [CrossRef]

41. Garb, C.; Leitner, M.; Tauscher, M.; Weidt, M.; Brunner, R. Statistical analysis of micropore size distributions in Al-Si castings evaluated by X-ray computed tomography. Int. J. Mater. Res. 2018, 109, 889-899. [CrossRef]

42. Borbély, A.; Csikor, F.F.; Zabler, S.; Cloetens, P.; Biermann, H. Three-dimensional characterization of the microstructure of a metal-matrix composite by holotomography. Mater. Sci. Eng. A 2004, 367, 40-50. [CrossRef]

43. Isaac, A.; Sket, F.; Reimers, W.; Camin, B.; Sauthoff, G.; Pyzalla, A.R. In situ 3D quantification of the evolution of creep cavity size, shape, and spatial orientation using synchrotron X-ray tomography. Mater. Sci. Eng. A 2008, 478, 108-118. [CrossRef]

44. Kroupa, A.; Dinsdale, A.T.; Watson, A.; Vrestal, J.; Vízdal, J.; Zemanova, A. The development of the COST 531 lead-free solders thermodynamic database. J. Miner. Met. Mater. Soc. 2007, 59, 20-25. [CrossRef] 
45. Schindelin, J.; Arganda-Carreras, I.; Frise, E.; Kaynig, V.; Longair, M.; Pietzsch, T.; Preibisch, S.; Rueden, C.; Saalfeld, S.; Schmid, B.; et al. Fiji: An open-source platform for biological-image analysis. Nat. Methods 2012, 9, 676-682. [CrossRef] [PubMed]

46. Doube, M.; Klosowski, M.M.; Arganda-Carreras, I.; Cordelières, F.P.; Dougherty, R.P.; Jackson, J.S.; Schmid, B.; Hutchinson, J.R.; Shefelbine, S.J. BoneJ: Free and extensible bone image analysis in ImageJ. Bone 2010, 47, 1076-1079. [CrossRef] [PubMed]

47. Hildebrand, T.; Rüegsegger, P. A new method for the model-independent assessment of thickness in three-dimensional images. J. Microsc. 1997, 185, 67-75. [CrossRef]

48. Chawla, N.; Sidhu, R.S.; Ganesh, V.V. Three-dimensional visualization and microstructure-based modeling of deformation in particle-reinforced composites. Acta Mater. 2006, 54, 1541-1548. [CrossRef]

49. Mokhtari, O.; Nishikawa, H. Correlation between microstructure and mechanical properties of Sn-Bi-X solders. Mater. Sci. Eng. A 2016, 651, 831-839. [CrossRef]

50. Lai, Z.; Ye, D. Microstructure and fracture behavior of non eutectic Sn-Bi solder alloys. J. Mater. Sci. Mater. Electron. 2016, 27, 3182-3192. [CrossRef]

51. Wijaya, A.; Eichinger, B.; Chamasemani, F.F.; Sartory, B.; Hammer, R.; Maier-Kiener, V.; Kiener, D.; Mischitz, M.; Brunner, R. Multi-method characterization approach to facilitate a strategy to design mechanical and electrical properties of sintered copper. Mater. Des. 2020, 197, 109188. [CrossRef]

52. Bieler, T.R.; Zhou, B.; Blair, L.; Zamiri, A.; Darbandi, P.; Pourboghrat, F.; Lee, T.K.; Liu, K.C. The role of elastic and plastic anisotropy of $\mathrm{Sn}$ in recrystallization and damage evolution during thermal cycling in SAC305 solder joints. J. Electron. Mater. 2012, 41, 283-301. [CrossRef]

53. Martin, C.L.; Brown, S.B.; Favier, D.; Suéry, M. Shear deformation of high solid fraction ( $>0.60)$ semi-solid SnPb under various structures. Mater. Sci. Eng. A 1995, 202, 112-122. [CrossRef]

54. Fuloria, D.; Lee, P.D. An X-ray microtomographic and finite element modeling approach for the prediction of semi-solid deformation behaviour in Al-Cu alloys. Acta Mater. 2009, 57, 5554-5562. [CrossRef]

55. Kareh, K.M.; Lee, P.D.; Atwood, R.C.; Connolley, T.; Gourlay, C.M. Revealing the micromechanisms behind semi-solid metal deformation with time-resolved X-ray tomography. Nat. Commun. 2014, 5, 1-7. [CrossRef]

56. Cai, B.; Karagadde, S.; Yuan, L.; Marrow, T.J.; Connolley, T.; Lee, P.D. In situ synchrotron tomographic quantification of granular and intragranular deformation during semi-solid compression of an equiaxed dendritic Al-Cu alloy. Acta Mater. 2014, 76, 371-380. [CrossRef]

57. Carman, P.C. Fluid flow through granular beds. Chem. Eng. Res. Des. 1997, 75. [CrossRef] 